\title{
Organizational Demographic Faultlines: Their Impact on Collective Organizational Identification, Firm Performance, and Firm Innovation
}

\section{Ulrich Leicht-Deobald ${ }^{a}$, Hendrik Huettermann ${ }^{b}$, Heike Bruch ${ }^{a}$ and Barbara S. Lawrence ${ }^{c}$ \\ ${ }^{a}$ University of St. Gallen; ${ }^{b}$ Bundeswehr University Munich; ${ }^{c}$ University of California, Los Angeles}

ABSTRACT In this study, we seek to understand the consequences of demographic faultines at the organizational level. Drawing from the faultline and cross-categorization literature, we suggest that organizational demographic faultlines (based on age and gender) have the potential to either reduce or enhance employees' collective organizational identification and, thereby, indirectly influence firm performance and innovation. Whether organizational demographic faultlines have detrimental or beneficial effects depends on the functional heterogeneity within faultline-based demographic subgroups, where heterogeneity is defined as the extent to which subgroup members belong to different functional departments. We theorize that this functional heterogeneity alters the degree of social integration between demographic subgroups. Results from a multisource field study of demographic faultlines among 5,495 employees in 82 small and medium-sized firms (<250 employees) support our model. We demonstrate that organizational demographic faultlines have important consequences, and we show that functional heterogeneity changes whether these consequences are negative or positive.

Keywords: collective organizational identification, firm innovation, firm performance, functional heterogeneity, organizational demographic faultlines

\section{INTRODUGTION}

Demographic faultlines are hypothetical dividing lines that split a group into subgroups based on one or more demographic attributes of its members (Lau and Murnighan, 1998). The vast majority of prior research has focused on demographic faultlines at

Address for reprints: Ulrich Leicht-Deobald, Institute for Business Ethics, University of St. Gallen, Girtannerstrasse 8, 9010 St. Gallen, Switzerland (ulrich.leicht-deobald@unisg.ch).

This is an open access article under the terms of the Creative Commons Attribution License, which permits use, distribution and reproduction in any medium, provided the original work is properly cited. 
the small-group level (Meyer et al., 2014; Thatcher and Patel, 2012), suggesting that faultlines hamper intrateam social integration and coordination by raising the risk of intergroup bias between subgroups (Meyer et al., 2014). Accordingly, most research at the small-group level finds that demographic faultlines increase conflict and reduce cohesion, thereby impairing team viability and performance (Thatcher and Patel, 2012).

The rising interest in the faultline concept has also led to several initial attempts to examine demographic faultlines at the organizational level. In a first effort, Lawrence and Zyphur (2011) proposed that organizational faultlines develop in a way similar to faultlines in small groups in that individuals identify with demographic attributes, such as age and gender, and are therefore 'likely to psychologically orient themselves toward others who share those attributes' (p. 35). In a sample of 358 managers from a large utility company with more than 9,000 employees, the authors found that managers in the same demographic subgroup had more social ties with each other than they had with managers from other demographic subgroups. Although Lawrence and Zyphur's (2011) study provided support for the existence of faultlines at the organizational level, their analysis did not include consequences of organizational faultlines, because it focused on a single organization.

In another study, Bezrukova et al. (2016) examined the consequences of organizational demographic faultlines in a sample of 30 Major League Baseball teams exhibiting organization-like properties (i.e., strategic goals, formal hierarchy, and a nested structure of formal sub-teams). Their study found a negative effect of organizational demographic faultlines on the number of games a team won during the season. While constituting a valuable initial attempt to examine the consequences of organizational demographic faultlines, the study had two notable limitations. First, the teams under study were relatively small, encompassing 25 members each, who were divided into four formal subteams of at least four individuals. Hence, the results may not be generalizable to larger organizations (Larson, 2009). Second, Bezrukova et al. (2016) conceptualize organizational demographic faultlines as the mean level of the four sub-teams' demographic faultlines. Therefore, their study does not analyse faultlines that directly emerge at the organizational level.

In sum, the literature on faultlines emerging on the organizational level is still in its infancy and has to date received only limited theoretical consideration. While there is initial evidence on the existence of organizational faultlines, prior research has largely been silent on whether, how, and when such faultlines may influence important organizational outcomes, which gives rise to the following questions: (a) How do organizational faultlines relate to organizational effectiveness, and (b) what are the theoretical mechanisms underlying the relationship? (c) What are critical boundary conditions that need to be considered for explaining their effects? Thus far these questions have remained unanswered. Building on Lawrence and Zyphur's (2011) work, we aim to fill this void by developing and testing a theoretical model on the firm-level consequences of organizational demographic faultlines. Drawing from faultline theory (Lau and Murnighan, 1998) and literature on cross-categorization (Sawyer et al., 2006), we theorize and empirically examine how organizational demographic faultlines relate to employees' collective organizational identification, and how they thereby influence firm performance and firm innovation. Collective organizational identification can be defined as the average 
emotional significance that employees attach to their organizational membership (Mael and Ashforth, 1992), which has been proposed as a key lever for organizational effectiveness (Ashforth et al., 2008).

Specifically, we suggest that organizational demographic faultlines can either reduce or enhance employees' collective organizational identification depending on the functional heterogeneity within faultline-based demographic subgroups. Functional heterogeneity refers to the extent to which demographic subgroup members belong to different functional departments within the organization (Blau, 1977; Bunderson and Sutcliffe, 2002). Consider the following example, which illustrates the meaning of functional heterogeneity within demographic subgroups:

MedCom is a medium-sized medical technology firm in which different subgroups based on employees' demographic attributes exist. One demographic subgroup (subgroup A) consists of eight older men who work together in the IT unit. Some of them are friends, and some of them participate in the same activities after work. Another demographic subgroup is comprised of eleven young women (subgroup B) who work in different parts of the firm, such as marketing, R\&D, and purchasing. Some of them see each other privately after work and some are not even aware that this demographic subgroup of young women exists. Both demographic subgroups A and B signify strong organizational demographic faultlines, as both groups are homogenous with regard to members' demographic attributes (i.e., old men versus young women). However, subgroup B is more heterogenous in terms of members' departmental affiliation than subgroup A.

When functional heterogeneity within demographic subgroups is low (as in subgroup A - older men from the IT department), subgroup members' demographic attributes and their department membership align. Drawing from faultline theory (Thatcher and Patel, 2012), this social structure most likely increases the peril of an intergroup bias toward other demographic subgroups created by organizational faultlines (i.e., a pattern of favouring one's own demographic subgroup over other demographic subgroups; Tajfel and Turner, 1986). Consequently, tension and friction emerge between subgroups, thereby limiting employees' identification with the organization as a whole. In contrast, when functional heterogeneity within demographic subgroups is high (as in subgroup B - younger women from various departments), social relations and social integration between subgroups should improve (Thatcher and Patel, 2012). Thus, intergroup bias is likely to be reduced and demographic subgroup members may even develop an inclusive sense of identification with the organization as a whole (Brewer, 1991).

As a consequence of the decreased or enhanced levels of organizational identification, employees are likely to contribute differently to organizational goals and effectiveness (Ashforth et al., 2008). Therefore, we propose that organizational demographic faultlines indirectly influence firm performance and firm innovation through employees' collective organizational identification, depending on the functional heterogeneity within the faultline-based demographic subgroups. Figure 1 provides an overview of our theoretical model. 
Our manuscript makes three important theoretical contributions to the emerging field of research on organizational demographic faultline. First, we demonstrate that these faultlines have important organizational-level consequences (i.e., on collective organizational identification, firm performance, and firm innovation). This evidence matters for faultline theorywhen organizational demographic faultlines make a difference for organizations, we should theoretically care about them as scholars. Second, we offer a novel theoretical perspective on organizational faultlines by conceptualizing faultlines as an opportunity structure that accentuates similarities within and differences between faultline-based demographic subgroups (Lawrence and Shah, 2020). This understanding of an opportunity structure differs from the notion of faultlines at the small-group level, because members of demographic subgroups created by organizational faultlines might not necessarily have interpersonal interdependencies or interactions based on a common task. Nevertheless, their demographic group membership can have significant implications for their identification with the organization and their contribution to organizational success (Ashforth and Johnson, 2001). Third, we identify an important boundary condition of organizational demographic faultlines' effects. Functional heterogeneity within faultline-based demographic subgroups represents a theoretically important moderator that has significant implications for intergroup relations (Thatcher and Patel, 2012). As such, it affects whether demographic faultlines have negative or positive consequences. Further, organizations can, at least to some extent, influence functional heterogeneity within demographic subgroups, thereby providing them with an opportunity to actively take advantage of demographic faultlines.

\section{THEORY AND HYPOTHESES}

\section{Conceptualization of Organizational Demographic Faultlines}

Organizational demographic faultlines are hypothetical dividing lines that create demographic subgroups based on the alignment of organizational members' demographic attributes (Lawrence and Zyphur, 2011). Such faultline-generated demographic subgroups represent what Turner (1984, p. 530) refers to as a psychological group - that is,

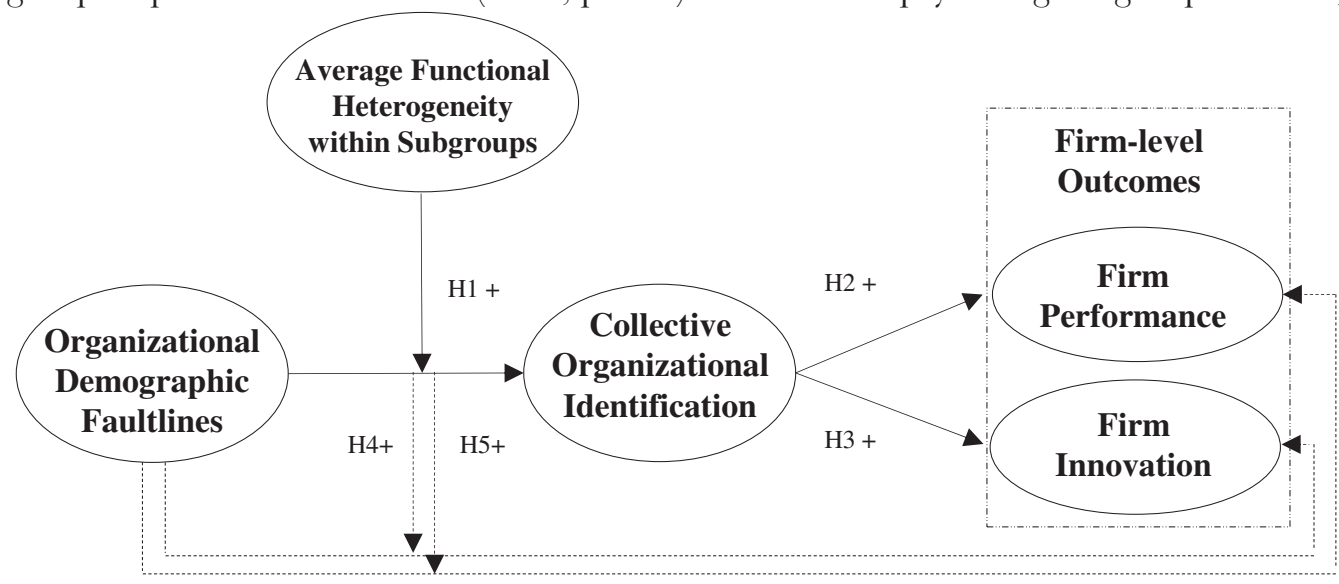

Figure 1. A theoretical model of organizational demographic faultlines and firm-level outcomes 
'a collection of people that $[\ldots]$ define themselves in terms of the same social category membership'. Although the members of psychological groups do not necessarily interact as members per se, their demographic identities have been argued to remain fairly salient (Ashforth and Johnson, 2001; see also Lawrence and Zyphur, 2011). Many demographic attributes, such as age and gender, are universal and highly visible, thus providing ready stimuli for social categorization (Milliken and Martins, 1996). When multiple demographic attributes are aligned, as in the case of faultlines, these attributes should become particularly salient (Lawrence, 2006).

As such, we propose that organizational demographic faultlines act as an opportunity structure that constrains organizational members' relations within and between demographic subgroups by accentuating their within-group similarities and between-group differences (Lawrence and Shah, 2020). This way, it offers organizational members a possibility to relate to demographically similar others. The notion of demographic subgroups as an informal opportunity structure does not necessarily entail social interaction with or even cognizance of all members of a demographic subgroup of similar others (see also Turner, 1984). Some subgroup members may know all other members of a subgroup, while others may know only some other members. As such, we see those demographic subgroups more as an informal opportunity structure that individuals can tap into than as a social network of individuals regularly interacting with one other.

In line with prior faultline research (e.g., Homan et al., 2007; Thatcher and Patel, 2012), we suggest that the effects of organizational demographic faultlines depend on the extent to which these faultlines become activated. As Lau and Murnighan (2005, p. 646) point out, faultlines 'have their greatest effect when a faultline-related issue arises' that turns potential faultlines into active ones, because an issue makes the underlying demographic subgroups salient (Jehn and Bezrukova, 2010). Prior research suggests that such faultline-related issues (sometimes also referred to as faultline activators or triggers) can evolve around aspects of the organizational social structure, such as informal network position (Ren et al., 2015), geographic location (Polzer et al., 2006), or even simple contact (Chrobot-Mason et al., 2009). Our study focuses on the extent to which demographic subgroups are comprised of members from different functional departments (i.e., functional heterogeneity within demographic subgroups; Blau, 1977; Bunderson and Sutcliffe, 2002). We suggest that functional heterogeneity makes demographic subgroups salient, because it is a structural property that alters whether subgroup members predominantly interact with members of the same demographic subgroup or engage in social relations across subgroup boundaries.

\section{Organizational Demographic Faultlines and Collective Organizational Identification: Functional Heterogeneity within Subgroups as a Moderator}

We draw from the literature on faultlines (Thatcher and Patel, 2012) and crosscategorization (Sawyer et al., 2006) to explain why organizational faultines can have either negative or positive effects on important organizational outcomes. Crosscategorization refers to a situation in which at least one additional social attribute cuts across (i.e., does not align with) demographic faultlines, thereby reducing the exclusivity of demographic subgroup boundaries (Marcus-Newhall et al., 1993; Migdal et al., 1998; 
Sawyer et al., 2006; Thatcher and Patel, 2012). The extension of the cross-categorization argument from the small-group to the organizational level is based on the assumption of functional equivalence (Morgeson and Hofmann, 1999), as we expect that the crosscategorization mechanism works similarly at the organizational level as it works on the small-group level.

A central advantage of conceptually separating the effects of organizational demographic faultlines from the functional heterogeneity within the demographic subgroups created by those faultlines is that it allows us to compare two scenarios: one in which department membership is aligned with the demographic attributes of subgroup members, and one in which department membership is not aligned with demographic attributes. ${ }^{[1]}$ Figure 2 provides an illustration of the two scenarios. When functional heterogeneity within demographic subgroups is low, all demographic subgroup members are affiliated with the same functional department (see Figure 2, scenario C1). When functional heterogeneity within a demographic subgroup is high, its subgroup members are affiliated with a variety of different functional departments (see Figure 2, scenario C2). In this figure and in our further theorizing, we focus on employees' age and gender to illustrate the consequences of organizational demographic faultlines, because they represent two of the most salient demographic attributes (Ashforth and Johnson, 2001; Harrison et al., 1998), and therefore also serve as the basis of our empirical analysis (for a detailed discussion of our choice of these attributes, see the Method section).

When functional heterogeneity within demographic subgroups is low, subgroup members share three attributes - age, gender, and department membership (see Figure 2, scenario $\mathrm{C} 1$ ). The structural effect of low functional heterogeneity is that it predominantly reinforces the prevalence of within-subgroup relations, since individuals will mostly

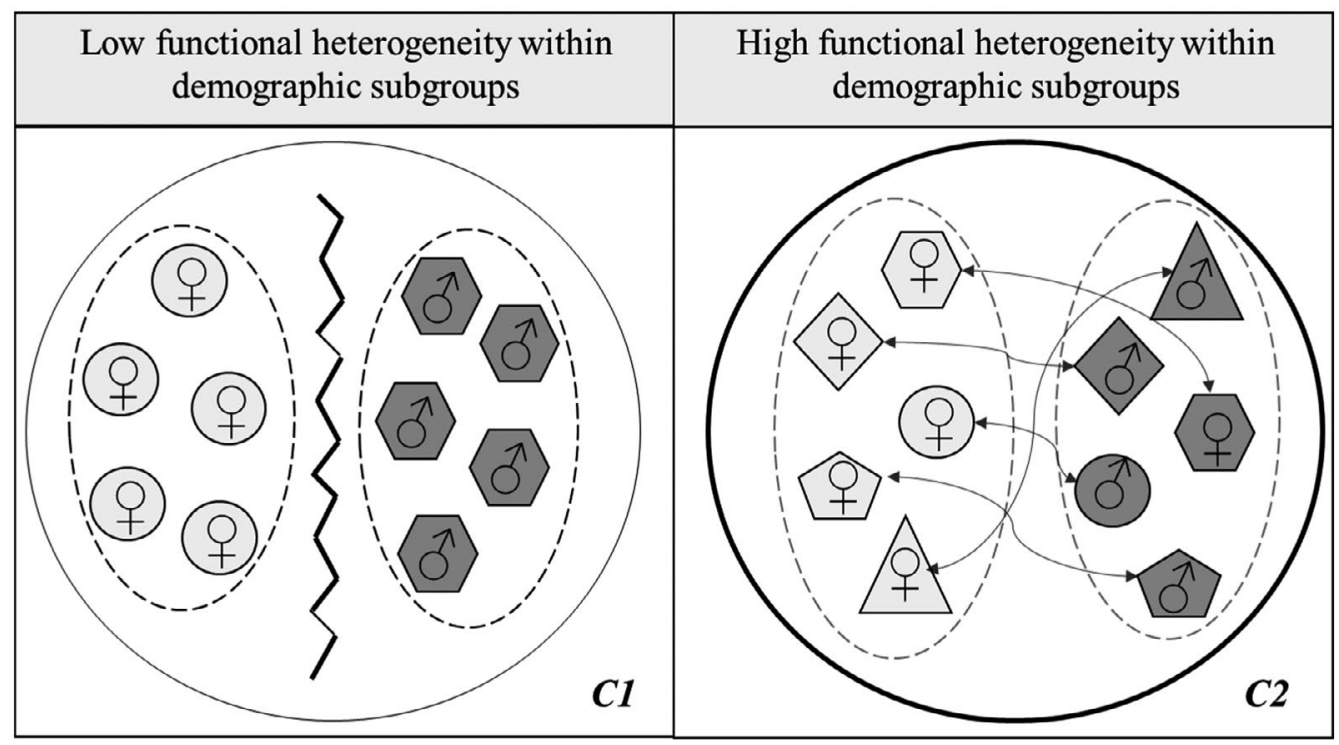

Figure 2. Illustration of interaction between organizational demographic faultines and functional heterogeneity within subgroups. Demographic attributes: $\delta=$ Male, $q=$ Female, $\|=$ Young, $\|=$ Old; functional department membership: $\mathrm{O}=$ Marketing, $\Delta=\mathrm{HR}, \diamond=$ Production, $\triangle=\mathrm{R} \& \mathrm{D}, \bigcirc=\mathrm{IT}$

(C) 2021 The Authors. Fournal of Management Studies published by Society for the Advancement of Management Studies and John Wiley \& Sons Ltd. 
interact with similar others in their subgroup based on the opportunity structure arising from the shared attributes (Ren et al., 2015). The faultline (Lau and Murnighan, 2005) and cross-categorization literature (Sawyer et al., 2006) suggests that the alignment of demographic attributes with the functional attribute of department membership should increase the strength of social categorization processes between demographic subgroups (Rico et al., 2012; Thatcher and Patel, 2012). Convergence between demographic attributes and department membership is likely to accentuate the risk of intergroup bias between subgroups, thereby creating friction and conflict (Thatcher et al., 2003). In such a situation, organizational faultlines could harm individuals' organizational identification, as subgroup members tend to identify more with their demographic subgroup (e.g., younger female members) than with the organization as a whole, which also encompasses members of other demographic subgroups (e.g., older male organizational members). Therefore, at the organizational level, demographic faultlines are likely to have negative consequences for employees' collective organizational identification.

In contrast, when functional heterogeneity within demographic subgroups is high, subgroup members are affiliated with different functional departments (as depicted in Figure 2, scenario C2). This intersection of demographic subgroups and functional departments should increase the social integration and intergroup relations between various subgroups, thereby improving opportunities for subgroup members to interact with similar others across subgroup boundaries (Mäs et al., 2013). As faultline theory (Lau and Murnighan, 2005) suggests, functional heterogeneity can mitigate the risk of subgroup formation and intergroup bias emanating from demographic faultlines. Situations in which a certain attribute is not clearly distinguishable between subgroups have been described as cross-categorization and are believed to weaken the strength of faultine alignment (Rico et al., 2012; Sawyer et al., 2006). In other words, when members of demographic subgroups come from different departments in the organization (i.e., show high levels of functional heterogeneity), demographic subgroup members most likely perceive fewer inter-subgroup differences (Thatcher and Patel, 2012). Consequently, devaluing other demographic subgroups that are also part of the organization should be reduced. This may serve as a buffer against the negative effect of demographic faultlines on subgroup members' identification with the organization. In line with this assumption, Marcus-Newhall et al. (1993) found that when individuals' subgroup membership and their role assignments were cross-categorized, they showed less intergroup bias than when their demographic subgroup membership and role assignments converged. Further, Migdal et al.'s (1998) meta-analysis at the small-group level demonstrates that cross-categorization reduces intergroup bias.

Going beyond the mere neutralization of organizational demographic faultlines' potential negative consequences, we suggest that improved social integration between demographic subgroups should also help subgroup members develop a more inclusive sense of identification with the organization as a whole. This rationale is in line with the notion of optimal distinctiveness (Brewer, 1991) that has been adopted in the faultine literature (e.g., Gibson and Vermeulen, 2003; Ormiston and Wong, 2012; Phillips et al., 2004). The optimal distinctiveness argument suggests that individuals have a need for differentiation (i.e., to be valued for their uniqueness and distinct qualities) as well as a need for inclusion (i.e., to belong to a larger collective). Specifically, Brewer (1996, p. 297) 
suggests that 'social structures that are not nested hierarchies but are characterized instead by cross-cutting roles and social categories' are likely to satisfy the need for differentiation. Hence, the intersection of demographic subgroups and functional departments should allow subgroup members to experience a sense of differentiation (Brewer, 1991). In terms of maintaining an optimal balance between differentiation and inclusion, this should also activate their need for inclusion with a superordinate higher-order category and trigger readiness to also identify with the organization as a whole (Brewer, 1999). In a similar vein, the organizational identification literature proposes that organizations 'provide [a] context within which local identities may flourish' (Ashforth and Johnson, 2001, p. 39) and may be considered as a 'home' or a 'vehicle' (Russo, 1998, p. 102) for expressing lower-order identities based on demographic subgroups, thereby increasing collective organizational identification.

In line with this argument, the faultline literature at the small-group level provides initial support for the notion of optimal distinctiveness, suggesting that subgroups can function as 'supportive cohorts' (Gibson and Vermeulen, 2003, p. 203) and provide 'pockets of social support' (Nishii and Goncalo, 2008, p. 10), thereby promoting a feeling that one's particular stance is valued (Bezrukova and Uparna, 2009). Moreover, initial empirical work points to positive faultline effects at the small-group level (e.g., Carton and Cummings, 2013; Chung et al., 2015; Gibson and Vermeulen, 2003). For example, Lau and Murnighan (2005) found that members of strong-faultline groups felt more psychological safety and satisfaction, and experienced less relationship conflict than members of weak-faultline groups. Similarly, Ren et al. (2015) showed that in strong-faultline teams, bridging friendship ties between subgroups increased the teams' task performance. Finally, Mäs et al. (2013) demonstrated that even in small teams with strong faultlines, social integration prevailed over subgroup polarization when taking cross-categorization between subgroups into account. Based on our theoretical considerations and extant empirical findings, we therefore suggest:

Hypothesis 1: Functional heterogeneity within demographic subgroups moderates the relationship between organizational demographic faultlines and collective organizational identification, such that the relationship is negative when functional heterogeneity is low and positive when functional heterogeneity is high.

\section{Consequences of Collective Organizational Identification for Firm-Level Outcomes}

Organizational identification refers to a specific form of social identification and encompasses individuals' attaching value and emotional significance to their organizational membership (Mael and Ashforth, 1992; Tajfel, 1978). By incorporating aspects of the organization's goals, values, and norms into their self-concept, organizationally identified employees become 'a microcosm of the organization such that acting on behalf of the organization is tantamount to acting on behalf of themselves' (Ashforth et al., 2008, p. 337). Accordingly, organizational identification has been found to shape a multitude of employee attitudes and behaviours that benefit the organization (Ashforth 
et al., 2008; Haslam and Ellemers, 2005; Lee et al., 2015; Pratt, 1998; Riketta, 2005; van Knippenberg, 2000).

As for the consequences of organizational identification, Ashforth and Mael (1989) propose that employees show increased levels of support and effort on behalf of the organization, thus directly contributing to organizationally-focused goals and outcomes (Riketta and van Dick, 2005; van Knippenberg, 2000). Additionally, they suggest that organizational identification enhances cooperation, collaboration, and cohesion among employees, which facilitates the exchange of information, knowledge, and resources (Ashforth and Mael, 1989; Grice et al., 2006). Drawing from these seminal works and the established body of literature on organizational identification, we therefore suggest that collective organizational identification benefits two important organizational-level outcomes: firm performance and firm innovation.

Regarding firm performance, high levels of collective organizational identification contribute to organizational goal achievement through both employees' individual actions and potential social influence processes among employees. As seminal organizational theory suggests, attitudes are a particularly forceful driver of individuals' behaviour and actions at work. These work-related behavioural responses, in turn, can significantly influence organizational effectiveness (Kopelman et al., 1990; McGregor, 1960). Organizationally identified employees' sense of self is closely tied to the collective, which often entails a strong commitment to and support for organizational goals (Albert et al., 2000; Haslam and Ellemers, 2005). One major way of reifying the productivity-related behavioural response to these feelings of attachment and commitment is to show high individual effort and productivity-relevant behaviour for the sake of organizational goals. Thus, employees who are high identifiers are likely to show high levels of job performance (Haslam and Ellemers, 2005; van Knippenberg, 2000), which is a major precursor of organizational performance (Kopelman et al., 1990).

Further, as prior research has shown, the efforts of individuals in organizations will most likely also have an effect on their peers through social comparison and contagion effects (Barrick et al., 2015; Gardner et al., 2011). That is, employees compare their own efforts with those of their colleagues to figure out appropriate behaviour. Thus, in organizations with high levels of collective organizational identification, employees are likely to experience a normative influence from the organizational context to adapt their effort levels to match those of high-performing peers. This assumption is in line with prior collective-level research showing that attitudes and commitment among employees tend to converge in organizations, creating behavioural norms that are consistent with the shared attitude (Morgeson and Hoffmann, 1999). Thus, the productivity-related behaviours of highly identified employees are likely to transmit throughout the organization, so that the impact of collective organizational identification on collective (i.e., organizational-level) performance becomes particularly pronounced (Gardner et al., 2011; Ostroff, 1992). In support of these assumptions, prior research has found organizational identification to significantly foster individuals' job performance (Lee et al., 2015). Moreover, there is evidence that high levels of collective commitment benefit organizational-level performance (Kunze et al., 2011; Ostroff, 1992).

In addition, also firm innovation is likely to benefit from high levels of collective organizational identification. Again, positive effects can be expected through both individuals 
and their interactions. Employees who strongly identify with their organization are likely to be more creative, which is a basic prerequisite for increased innovation. Employees identifying with their firm adopt organizational goals as their own personal goals and thus will most likely experience intrinsic motivation in working toward these goals (Loi et al., 2014; Riketta, 2005), with intrinsic motivation serving as a key driver of creativity and innovation (Hennessey and Amabile, 2010; van Knippenberg and van Schie, 2000). Moreover, since individuals who strongly identify with their organization feel a deep desire to support the organization's goals in order to maintain and enhance their self-esteem (Ashforth and Mael, 1989), they are likely to explore unconventional and innovative approaches even when facing unprecedented or difficult situations at work. Therefore, in organizations with high levels of collective organizational identification, the individual employees will show higher levels of creativity and are more likely to develop and implement innovative ideas, which will benefit the organization's overall level of innovativeness.

Further, organizational identification also enhances cooperation and collaboration between employees, which most likely facilitates the transmission and exchange of information, knowledge, and ideas throughout the organization (Ashforth and Mael, 1989). Thus, high levels of collective organizational identification ensure that tasks and challenges requiring creativity and innovation are tackled with the best pool of knowledge and information available from the employees in the organization, who work together for sharing information and developing new ideas and solutions. This increased flow and use of information together with the strongly identified employees' high motivation to serve the organization's goals are likely to foster the development of creative ideas and innovations that are also actionable and can realistically be implemented. Accordingly, prior research has shown that organizational identification fosters creativity, information sharing, and knowledge transfer among employees and groups within organizations (Carmeli et al., 2007; Grice et al., 2006; Kane et al., 2005). Hence, an increase in firm innovation can be expected.

In sum, the evidence in support of the beneficial consequences of collective organizational identification bolsters the following hypotheses:

Hypothesis 2: There is a positive relationship between collective organizational identification and firm performance.

Hypothesis 3: There is a positive relationship between collective organizational identification and firm innovation.

\section{Integrated Model}

Seminal frameworks in the diversity literature have repeatedly emphasized the role of social identity processes for translating the effects of workforce demographic composition into organizational effectiveness (e.g., Cox, 1994; van Knippenberg et al., 2004; Williams and O'Reilly, 1998). In this regard, Cox's (1994) interactional model of diversity proposes that diversity influences employees' organizational identification as a major employee outcome, which in turn has an effect on both first-level (i.e., creativity 
and innovation) and second-level (i.e., firm performance) organizational effectiveness. Concurring with these considerations, we propose that organizational demographic faultlines can either negatively or positively relate to collective organizational identification, depending on the functional heterogeneity within the demographic subgroups (Hypothesis 1). Additionally, we suggest that collective organizational identification most likely benefits both firm-level performance and innovation (Hypotheses 2 and 3). Taken together, we propose the following conditional indirect effects:

Hypothesis 4: Functional heterogeneity within demographic subgroups moderates the indirect relationship between organizational demographic faultines and firm performance (as mediated through collective organizational identification). The indirect relationship is negative when functional heterogeneity is low and positive when functional heterogeneity is high.

Hypothesis 5: Functional heterogeneity within demographic subgroups moderates the indirect relationship between organizational demographic faultlines and firm innovation (as mediated through collective organizational identification). The indirect relationship is negative when functional heterogeneity is low and positive when functional heterogeneity is high.

\section{METHOD}

\section{Data Collection}

We collected data from small and medium-sized enterprises (SMEs) in Germany in collaboration with a benchmarking agency as part of a larger research project. Due to their limited size, SMEs are particularly appropriate for testing our hypotheses, as we assume that their employees are likely to have a sufficient overview of the demographic composition of the firm's workforce to recognize certain demographic attributes of their colleagues. This provides the basis for our rationale that subgroups generated by organizational demographic faultlines may act as an opportunity structure. Thus, we included organizations with fewer than 250 organizational members in our analysis (European Commission, 2017). Before data collection began, the organizations' HR divisions sent emails to all employees to encourage their participation. The emails highlighted the importance of the study and assured confidentiality of responses. Three weeks after the data collection started, a reminder email was sent to non-respondents. To further incentivize the organizations, each firm received a benchmarking report in exchange for participating in the study.

We asked all organizational members to provide information on their demographic background and functional department membership (Survey_all). We believed participants would rate these social characteristics objectively because the data were expected to be easily assessable for self-rating. Furthermore, we gathered data on other variables (i.e., collective organizational identification, firm performance, and firm innovation) from three different sources to reduce common method variance (Podsakoff et al., 2003). 
First, we asked a randomly chosen quarter of the employees to rate their degree of organizational identification (Survey_A). We used employees for these ratings because they should be in the best position to rate their own feelings (Chan, 1998). Only 25 per cent of the employees were asked for their ratings owing to the design of the larger research project - employees in each organization had been randomly assigned to one of four different surveys. Three of these survey versions (Survey_B, Survey_C, and Survey_D) were reserved for the benchmarking agency (although we also used employees' demographic information and department membership from these surveys in our analysis). ${ }^{[2]}$ Second, we asked each company's top HR representative to rate firm performance and three additional control variables, namely organization size, industry affiliation, and firm understaffing (Survey_HR). Third, we collected data on firm innovation from the members of each firm's top management team (TMT) (Survey_TMT).

\section{Sample}

We distributed surveys to 82 organizations comprising 7,662 organizational members (an average of 93.44 individuals per SME; $S D=58.30$, min.: 20; max.: 246). Our final sample included a total of 5,495 organizational members (Survey_all), representing a withinorganization response rate of 71.72 per cent. Employees were mostly male (62.71 per cent), the average age was 39.42 years $(S D=4.18)$, and employees had been working for their firms for an average of 7.27 years $(S D=7.63)$. The typical TMT member was male (85.58 per cent), 47.20 years old $(S D=7.99)$, and had been with their company for 11.46 years $(S D=7.55)$. On average 2.77 ( $\mathrm{SD}=2.09)$ TMT members participated in each company. The top HR representatives were predominantly male (64.63 per cent) with an average age of $44.54(S D=8.81)$, and on average they had been working for their firms for 11.02 years $(S D=7.44)$. Most organizational members were affiliated with the marketing department (24.11 per cent), followed by IT (21.22 per cent), production (15.33 per cent), R\&D (10.48 per cent), customer service (6.01 per cent), finance (7.99 per cent), HR (3.77 per cent), logistics (3.02 per cent), public relations (2.34 per cent), support (2.19 per cent), purchasing (1.36 per cent), planning (1.23 per cent), the executive board's office ( 0.58 per cent), and medical care (0.38 per cent). On average, organizations were 28.87 years old $(S D=26.41)$, with the majority of firms stemming from the service sector (54.88 per cent), followed by those in the manufacturing (29.27 per cent), trade (8.53 per cent), and finance and insurance (7.32 per cent) industries.

\section{Measures}

Unless otherwise stated, all items were captured on a Likert-type scale ranging from (1) 'strongly disagree' to (7) 'strongly agree'. All the materials were presented in German. Two independent, bilingual researchers translated the items from English into German and then translated them back into English (Brislin, 1986).

Organizational demographic faultines. We used the average silhouette width (ASW) algorithm developed by Meyer and Glenz (2013) to compute organizational demographic faultlines. The ASW algorithm uses cluster analysis to identify the subgroup split associated with an entity's strongest faultline for groups with more than two homogeneous subgroups. 
Cluster analysis assigns individuals (i.e., organizational members) to different clusters (i.e., subgroups) based on their similarity, resulting in clusters that have maximum internal homogeneity and maximum heterogeneity between clusters (for more details on the procedure, see the Appendix). In our analysis, the ASW algorithm detected, on average, 4.67 faultline-based demographic subgroups per organization based on age and gender $(S D=1.60$ ) (average subgroup size $=12.23$ members, $S D=15.31$ ). For example, in a smaller organization of our sample with 35 employees the ASW algorithm distinguished three demographic subgroups: While Subgroup 1 consisted of 14 'younger women' (average age $=30.21$ years, $S D=3.19$ ), Subgroup 2 comprised of 12 'younger men' (average age $=32.50$ years, $S D=3.26$ ), and Subgroup 3 contained nine 'later middle-aged men' (average age $=43.00$ years, $S D=3.08$ ). In a larger organization with 113 employees, the ASW measure found six demographic subgroups, ranging from eight 'younger women' (Subgroup 1; average age $=29.50$ years, $S D=4.38$ ), 27 'younger men' (Subgroup 2; average age $=30.93$ years, $S D=3.46$ ), 27 'early middle-aged men' (Subgroup 3; average age $=39.56$ years, $S D=2.04$ ), 33 'later middle-aged men' (Subgroup 4 ; average age $=47.48$ years, $S D=2.66$ ), nine 'later middle-aged women' (Subgroup 5; average age $=46.56$ years, $S D=5.64$ ) to nine 'older men' (Subgroup 6; average age $=$ 58.78 years, $S D=2.17$ ).

We focused on employees' age and gender for calculating organizational demographic faultlines, since we expected these attributes to be the most salient for the organizational members in our sample. First, diversity researchers have referred to both age and gender as 'readily detectable' attributes (Milliken and Martins, 1996) that occur on the 'surface level' (Harrison et al., 1998). Due to their high visibility, age and gender are particularly likely to serve as a basis for social categorization processes and, thereby, lead to the formation of subgroups (Hogg and Abrams, 1988; Tajfel and Turner, 1986; van Knippenberg and Schippers, 2007). Further, age and gender have been argued to be meaningful social categories across time periods and cultures (Linton, 1942). Thus, we suggest they are of particular importance for our study's focus on faultlines at the organizational level. As prior research has pointed out, differences among employees are hard to detect with increasing group size (Lawrence and Zyphur, 2011). Hence, both age and gender should be easily discernable, even for people working in other departments of the firm.

Second, age and gender are both particularly salient in the context of our German sample. On the one hand, demographic changes and the aging workforce are major societal developments affecting the German workforce. According to the German Federal Statistical Office, the average age of the German working population has increased by about five years since 1991, rising to 43.4 years in 2017 (DeStatis, 2019). Further, the labour-force participation rate for women has increased, rising from 57 per cent in 1991 to 71 per cent in 2016 (DeStatis, 2018), which also reflects a major societal trend and increasing efforts to ensure gender equality in working life. As a consequence of these changes in the workforce composition and the public discourse emphasizing these demographic developments, age and gender are likely to be particularly salient in the context of our sample. On the other hand, race and ethnicity are not particularly pertinent diversity attributes in the German context. As Germany does not have an extensive history of immigration and a multi-cultural society like, for instance, the US, race and ethnicity are less relevant than age and gender with respect to faultlines and intergroup processes. ${ }^{[3]}$ 
Finally, the decision to use the ASW rather than other faultline measures was motivated by the ASW's ability to detect multiple subgroups and its high classification accuracy regarding individuals' subgroup membership. Also, the ASW algorithm allows us to combine categorical and numerical attributes (i.e., age, gender, and function) and is applicable to social units that have more than 10 members, which is necessary for calculating faultlines at the organizational level (Meyer et al., 2014). ${ }^{[4],[5]}$

Collective organizational identification. We measured collective organizational identification using five items adapted from van der Vegt and Bunderson (2005). We asked employees to rate the following items: (1) 'I feel a strong sense of belonging to this organization', (2) 'Working for this organization has a great deal of personal meaning to me', (3) 'I would be happy to work for this organization until I retire', (4) 'I think that I could easily become as attached to another organization as I am to this one' (recoded), and (5) 'I am proud to tell others that I work for this organization'. Consistent with prior research (e.g., Kearney and Gebert, 2009; van der Vegt and Bunderson, 2005), we used a directconsensus composition model (Chan, 1998) that averaged all items and aggregated them to the organizational level. The alpha coefficient was 0.93 .

Functional heterogeneity within subgroups. As outlined above, we used the ASW algorithm to identify individuals' demographic subgroup membership. ASW provides an assessment of individuals' expected class membership in a faultline-based demographic subgroup. We measured the extent to which demographic subgroup members differed in their functional department membership using Blau's heterogeneity index (Blau, 1977) as:

$$
H=1-\sum P_{k}^{2}
$$

where $\mathrm{P}$ represents the fractional share of different functional backgrounds belonging to the $\mathrm{k}^{\text {th }}$ faultline-based demographic subgroup (Harrison and Klein, 2007). As we assumed functional equivalence across levels of analysis (Morgeson and Hofmann, 1999), we conceptualized functional heterogeneity within demographic subgroups as an additive composition model (Chan, 1998). Additive composition models specify a straightforward functional relationship between constructs at different levels (i.e., the subgroup and organizational levels in our case). Thus, we mean-aggregated the scores of demographic subgroups' functional heterogeneity to the organizational level.

Firm performance. We assessed firm performance by asking the top HR representative of each firm to indicate the extent to which the company performed well by directly comparing it to its industry rivals on a seven-point scale ranging from (1) 'far below average' to (7) 'far above average'. This approach is consistent with Rogers and Wright (1998). As this measure was skewed, we log-transformed it.

Firm innovation. In line with seminal works in the innovation literature (see, in particular, Anderson et al., 2004; Crossan and Apaydin, 2010; Damanpour, 1991, 2020; Hage, 1999; West and Farr, 1990; Wolfe, 1994), we adopted a comprehensive understanding of firm innovation that encompasses both the generation of innovative ideas and their 
implementation, as well as different types of innovation (i.e., technical and administrative as well as product and process innovations). Hence, TMT members of the participating companies assessed firm innovation using the nine-item measure developed by Janssen (2001) that captures the different stages and types of organizational innovation (Kanter, 1988; West and Farr, 1990). Respondents indicated the extent to which employees in their organization engaged in the following activities: idea generation ('creating new ideas for improvement', 'searching out new working methods, techniques, or instruments', and 'generating original solutions for problems'), idea promotion ('mobilizing support for innovative ideas,' 'obtaining approval for innovative ideas,' and 'making important organizational members enthusiastic about innovative ideas'), and idea realization ('transforming innovative ideas into useful applications', 'introducing useful ideas into the work environment in a systematic way,' and 'evaluating the utility of innovative ideas'). Items were averaged and aggregated to the organizational level. The alpha coefficient was 0.95 .

Control variables. We controlled for twelve additional variables that may affect one or more of the outcomes in our model. First, we controlled for the mean and the diversity of the two focal demographic variables in our study. Hence, we included measures for mean age, age diversity, mean gender, and gender diversity in our model (van Knippenberg and Schippers, 2007). Following Harrison and Klein (2007), we calculated age diversity using the standard deviation, and gender diversity by applying the Blau index. Second, we controlled for the percentage of organizational members in a leadership position to rule out another potential micro-foundation for organizational demographic faultlines. Third, we accounted for possible firm understaffing, as this may be associated with both firm performance and firm innovation. We asked the HR representatives to assess the oneitem understaffing measure developed by Ganster and Dwyer (1995; see, e.g., also Berger et al., 2021; Huettermann and Bruch, 2019). Fourth, we controlled for organization size, which has been found to be significantly related to a range of employee attitudes and behaviours (e.g., Pierce and Gardner, 2004). We log-transformed this measure due to its skewed distribution. Fifth, following prior research that has shown that the age of organizations can be significantly related to their effectiveness (e.g., Choi and Shepherd, 2005), we included organizational age as a control variable. Finally, we classified the organizations in our sample into four industries - services, production, trade, and finance - as industry affiliation is related to organizational effectiveness (e.g., Dickson et al., 2006). ${ }^{[6]}$

\section{RESULTS}

\section{Aggregation Statistics and Discriminant Validity}

We computed within-group interrater agreement $\left(\mathrm{r}_{\mathrm{wg}(\mathrm{j})} ; \mathrm{James}\right.$ et al., 1984) and intraclasscorrelation coefficients (ICCs) to justify the aggregation of collective organizational identification and firm innovation to the organizational level. Collective organizational identification had an average $r_{w g(j)}$ value of 0.74 and ICG $[1,2]$ values of 0.15 and 0.74 , respectively. Organizational innovation had an average $r_{w g(j)}$ value of 0.88 and ICG $[1,2]$ 
values of 0.18 and 0.43 , respectively. These values provide adequate support for aggregation to the organizational level (LeBreton and Senter, 2008).

To ensure the construct validity of the latent variables (i.e., collective organizational identification and firm innovation), we conducted confirmatory factor analyses (CFAs) using Mplus 8.3 (Muthén and Muthén, 1998-2019). For firm innovation, we formed three parcels of indicators by averaging the three items of each subdimension, as recommended by Bagozzi and Edwards (1998).

A CFA of the two latent constructs (i.e., collective organizational identification and firm innovation) of our research model revealed that this baseline model exhibited very good fit with the data $\left(\chi^{2}[19]=22.05\right.$, CFI $=0.99$, TLI $=0.99$, RMSEA $\left.=0.04\right)$. All standardized factor loadings were above 0.40 and significant. Moreover, the average variance extracted (AVE) and the composite reliability (CR) of our multi-item measures met the standards commonly discussed in the literature (i.e., AVE > 0.50; CR > 0.60; Bagozzi and Yi, 1988; Fornell and Larcker, 1981). Collective organizational identification had an AVE of 0.76 and a CR of 0.94, while the corresponding figures for organizational innovation were 0.76 and 0.97 . In addition, the AVE for each construct exceeded the square of the correlation between the two variables $\left(r^{2}=0.08\right)$. We examined an alternative onefactor model with collective organizational identification and firm innovation loading on a common factor against the baseline two-factor model. The baseline model with the two-factor solution fit the data significantly better than the one-factor model $\left(\chi^{2}[20]=\right.$ 148.03, $\mathrm{CFI}=0.78, \mathrm{TLI}=0.69$, RMSEA $\left.=0.28, \Delta \chi^{2}=125,98, \Delta d f=1 ; \mathrm{p}<0.001\right)$. Hence, we concluded that the two latent constructs were empirically distinct.

\section{Descriptive Statistics}

Table I shows the descriptive statistics and correlations of our study variables. Organizational demographic faultlines are not directly related to collective organizational identification $(r=-0.09, \mathrm{p}=n s)$. Collective organizational identification is positively associated with firm performance $(r=0.33, \mathrm{p}<0.01)$ and firm innovation $(r=0.29, \mathrm{p}<0.05)$.

\section{Research Model}

We applied structural equation modelling with full information maximum likelihood (FIML) estimation to account for the missing data in organizational performance and organizational innovation observations, as FIML has been shown to outperform alternative missing data methods in structural equation modelling (Enders and Bandalos, 2001). ${ }^{[7]}$ The major advantage of FIML is that only those parameters that included organizational performance and organizational innovation were affected by the reduced sample size ( $n=72$ and $n=60$, respectively), while all observations of the other variables in our model could be retained $(\mathcal{N}=82)$.

We conducted our analyses using Mplus 8.3 (Muthén and Muthén, 1998-2019). The variables were mean-centred prior to the analyses to reduce potential problems of multicollinearity (Aiken and West, 1991). To check for issues of multicollinearity, we examined the variance inflation factor (VIF) of each independent variable. All VIF values were less than 5 , which is well below the cut-off of 10 , indicating that multicollinearity was 


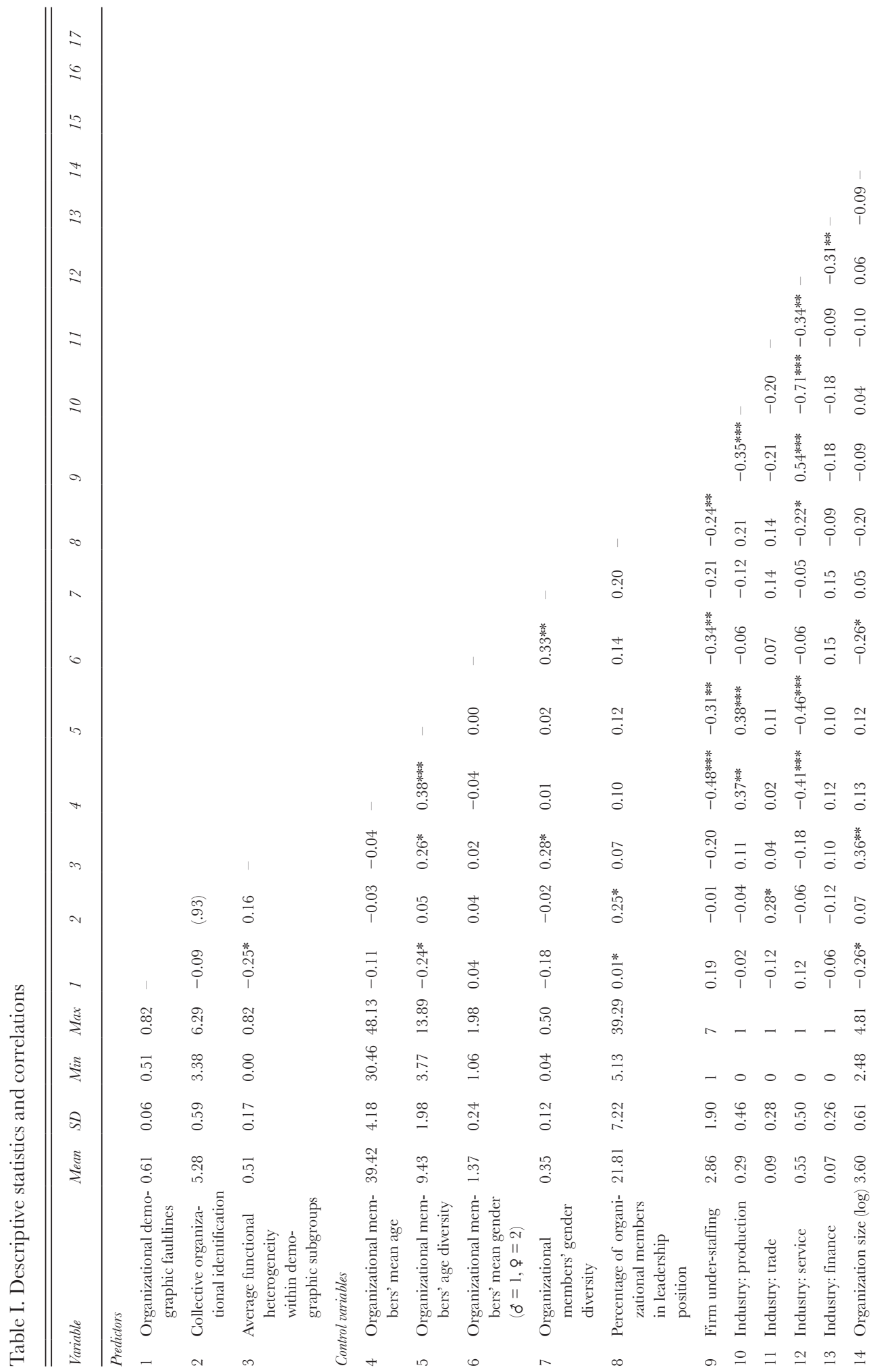


Organizational Demographic Faultlines

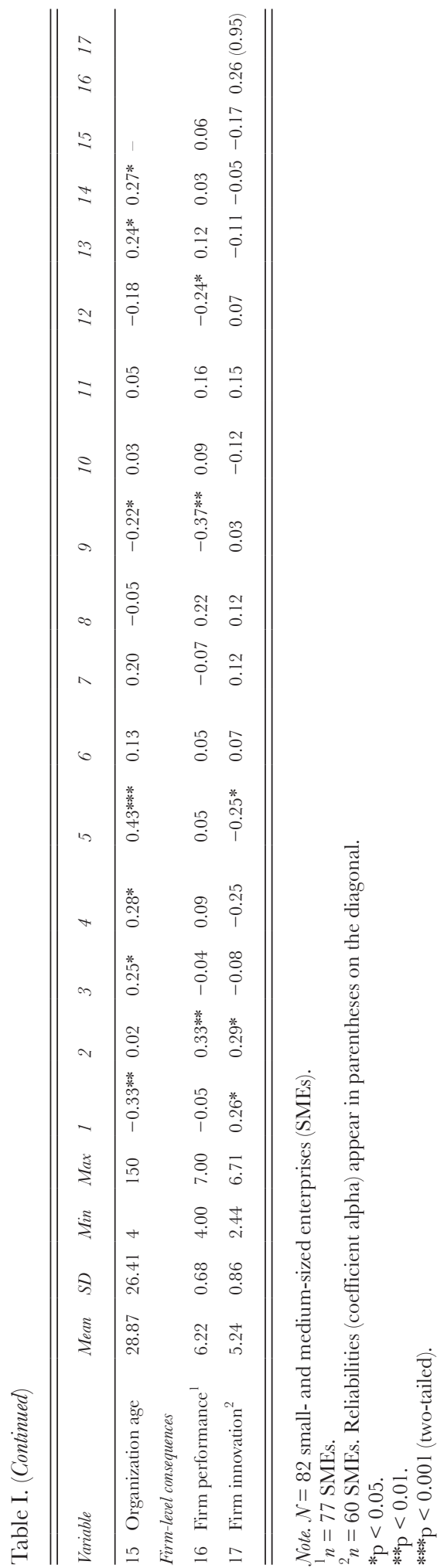

(C) 2021 The Authors. Fournal of Management Studies published by Society for the Advancement of Management Studies and John Wiley \& Sons Ltd. 


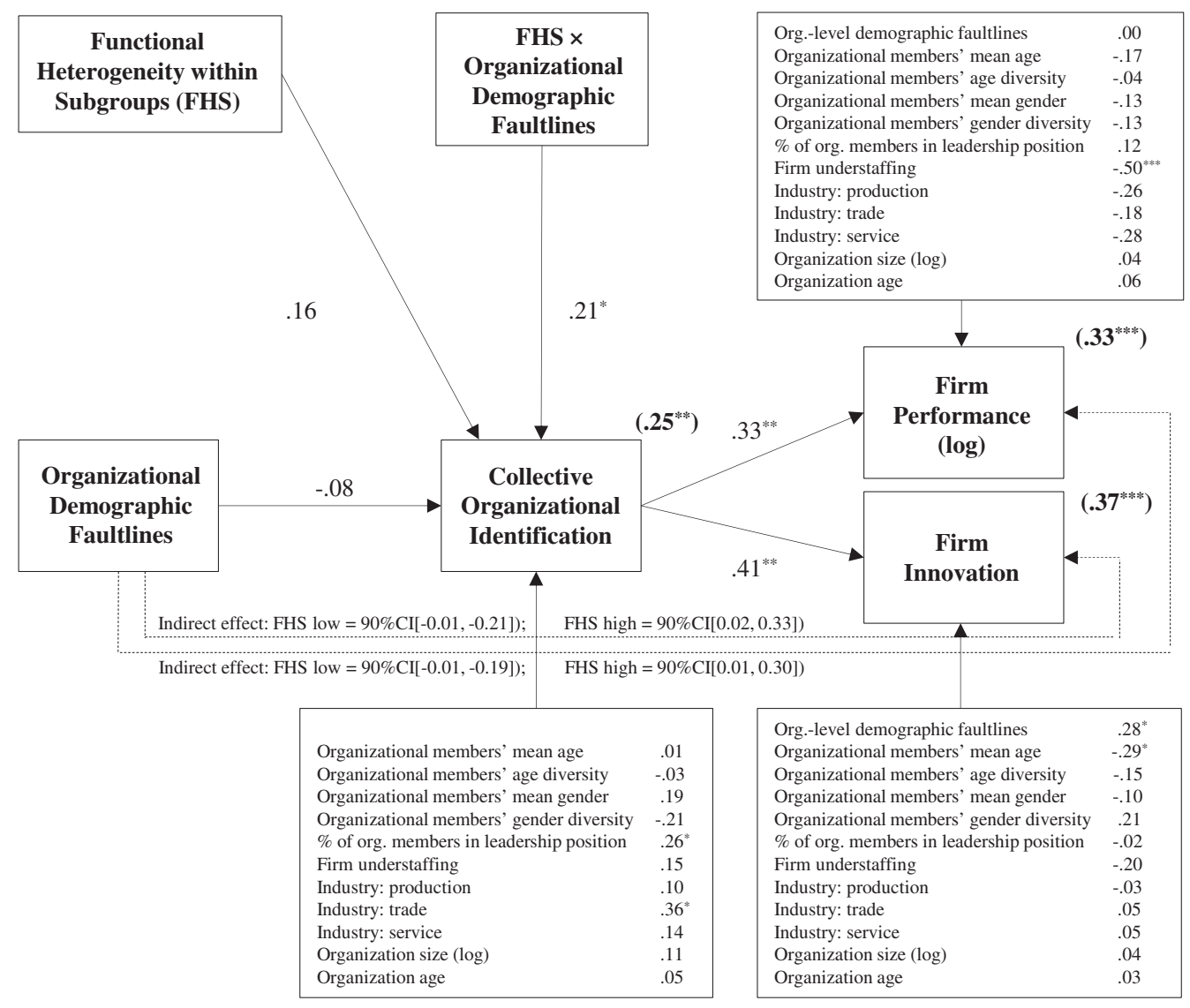

Figure 3. Structural equation modelling results for collective organizational identification, firm performance and firm innovation. Note. Standardized path coefficients are reported. R-squareds in parentheses. FHS $=$ Functional heterogeneity within subgroups. *p $<0.05 ; *$ p $<0.01 ; * * * p<0.001$ (two-tailed)

not a serious problem (Aiken and West, 1991). To test the interaction effect, we used a procedure similar to the one outlined in Aiken and West (1991) for regression analyses. Figure 3 presents the results of the structural equation modelling.

Hypothesis 1 predicts that the functional heterogeneity within demographic subgroups moderates the relationship between organizational demographic faultlines and collective organizational identification, such that the relationship is negative when functional heterogeneity is low and positive when functional heterogeneity is high. To test this hypothesis, we first specified a structural equation model without including the interaction term. This mediation-only model exhibited sufficient fit with the data $\left(\chi^{2}[103]=167.71\right.$, CFI $=0.90$, TLI $=0.85$, RMSEA $=0.09$ ). In the next step, we added the interaction term to inspect the incremental explained variance of the moderation. This moderated mediation model exhibited a good fit with the data $\left(\chi^{2}[111]=149.04, \mathrm{CFI}=0.94\right.$, TLI $=0.91$, RMSEA $=0.07)$ and matched the data significantly better than the mediationonly model $\left(\Delta \chi^{2}=18.67, \Delta d f=8, \mathrm{p}<0.001\right)$. Compared to the mediation-only model, the explained variance in collective organizational identification increased by 4 per cent 


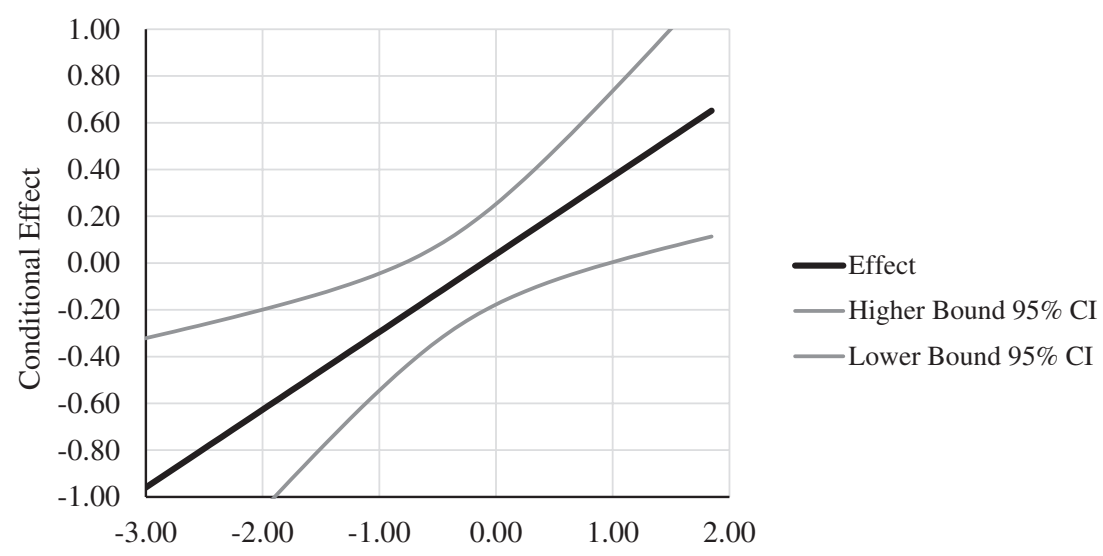

Functional Heterogeneity within Subgroups

Figure 4. Johnson-Neyman plot of the interaction between organizational demographic faultines and functional heterogeneity within subgroups. Note. Standardized effects and standardized values of functional heterogeneity within subgroups are reported.

$\left(\Delta \mathrm{R}^{2}=0.04, \mathrm{p}<0.01\right)$. As shown in Figure 3, the coefficient for the interaction between organizational demographic faultlines and functional heterogeneity within subgroups was significant $(\beta=0.21, S E=0.10, \mathrm{p}<0.05)$. To gain a deeper understanding of the shape of the interaction, we calculated the simple slopes. Following the procedure recommended by Aiken and West (1991), we classified functional heterogeneity within subgroups into a low group (-1 SD) and a high group (+1 SD), and then tested the significance of the simple slopes. This analysis revealed that the slope was negative and significant at low levels of the moderator $(\beta=-0.31, S E=0.13, \mathrm{p}<0.05$, whereas the slope was positive and significant at high levels of functional heterogeneity within subgroups $(\beta$ $=0.39, S E=0.19, \mathrm{p}<0.05)$.

Additionally, we calculated exact regions of significance for the moderation using 95 per cent bias-corrected confidence intervals (CIs) and illustrated the interaction using a Johnson-Neyman plot (see Figure 4). We found that when the standardized values of functional heterogeneity were -0.78 or lower, organizational demographic faultlines had a negative and significant relationship with collective organizational identification $(\beta$ at this lower transition point was -0.22 (CI $[-0.01,-0.45])$. Additionally, when functional heterogeneity reached its minimum standardized sample value of -3.05 the strength of this negative relationship increased up to a $\beta$ of -0.98 (CI $[-0.33,-1.63])$. In contrast, when the standardized values of functional heterogeneity were 0.98 or higher, organizational demographic faultlines had a positive and significant relationship with collective organizational identification $(\beta$ at this upper transition point was 0.36 , CI [0.01, 0.72]). Further, when functional heterogeneity arrived at its maximum standardized sample value of 1.85 the strength of the positive association grew up to $\beta$ of 0.65 (CI [0.11, 1.19]). As such, the link between organizational demographic faultlines and collective organizational identification was negative and significant for 16 organizations (20 per cent), 
whereas it was positive and significant for 14 organizations (17 per cent) in our sample. These findings support Hypothesis 1.

Hypothesis 2 predicts that collective organizational identification is positively associated with firm performance. As shown in Figure 3, the relationship between collective organizational identification and firm performance was positive and significant $\beta=0.33$, $S E=0.10, \mathrm{p}<0.01)$. This supports Hypothesis 2 .

Hypothesis 3 predicts that collective organizational identification is positively associated with firm innovation. As shown in Figure 3, the relationship between collective organizational identification and firm innovation was positive and significant $\beta=0.41$, $S E=0.13, \mathrm{p}<0.01)$. This finding supports Hypothesis 3 .

Hypothesis 4 predicts that functional heterogeneity within subgroups moderates the indirect relationship between organizational demographic faultlines and firm performance through collective organizational identification, such that the relationship is negative at low levels of the moderator and positive when functional heterogeneity is high. To test this hypothesis, we used the procedure outlined by Preacher and Hayes (2008) to compute bias-corrected confidence intervals (CIs) with 1,000 bootstrapping re-samples of this conditional indirect relationship. We applied 90 per cent bias-corrected CIs because we exactly specified the direction of the conditional indirect relationship in our hypothesis. Bootstrapping techniques are superior to the Sobel test for assessing indirect relationships because they are non-parametric, and therefore do not rely on the assumption of normality, which is generally violated when testing indirect relationships (Preacher and Hayes, 2008). When functional heterogeneity within subgroups was low, organizational demographic faultlines were negatively related to firm performance through collective organizational identification (low: $\mathrm{a} \times \mathrm{b}=-0.10$, BootCI $[-0.01,-0.19]$ ). In contrast, when functional heterogeneity was high, organizational demographic faultlines were significantly positively related to firm performance through employees' collective organizational identification (high: $\mathrm{a} \times \mathrm{b}=0.13$, BootCI [0.01, 0.30]). In addition, we assessed Hayes' (2015) index of linear moderated mediation, which evaluates whether an indirect relationship varies as a function of a moderating variable. Again, we used non-parametric bootstrapping because this technique does not rely on the assumption of normality. The bootstrapped 95 per cent bias-corrected CI of the index of linear moderated mediation did not include zero (index of moderated mediation $=1.16$, BootCI $[0.18$, 2.86]). This supports Hypothesis 4.

Hypothesis 5 predicts that the functional heterogeneity within demographic subgroups moderates the indirect relationship between organizational demographic faultlines and firm innovation through collective organizational identification, such that the relationship is negative when functional heterogeneity is low and positive when the moderator is high. To test this hypothesis, we again applied the bootstrapping procedure described above (Preacher and Hayes, 2008). When functional heterogeneity within subgroups was low, organizational demographic faultlines were negatively related to firm innovation through collective organizational identification (low: a $\times \mathrm{b}=-0.11$, BootCI [-0.01, $-0.21])$. In contrast, at high levels of the moderator, organizational demographic faultlines were positively related to firm innovation through collective organizational identification (high: $\mathrm{a} \times \mathrm{b}=0.14$, BootCI [0.02, 0.33]). Using a bootstrapped 95 per cent bias-corrected CI, Hayes' (2015) index of linear moderated mediation did not include 
zero (index of moderated mediation $=12.45$, BootCI $[0.41,48.48])$. Hence, Hypothesis 5 is supported. [8],[9]

\section{Robustness Check}

We captured firm performance using one item rated by organizations' top HR representatives, which may raise concerns about the validity of that measure. To further strengthen the robustness of our findings, we obtained additional and more comprehensive performance ratings from members of the top management team (TMT) for a subsample of the companies in our analysis. Specifically, we contacted the benchmarking agency with which we had conducted our study and asked whether any of the companies had participated in other benchmarking analyses in the two years following our initial data collection. This was the case for 30 of the companies. The performance ratings in these subsequent benchmarking analyses were provided by TMT members and were captured using two items each pertaining to organizational performance (the company's current financial situation and company growth) and operational performance (employee productivity and employee retention), based on Combs et al. (2005). TMT members were asked to rate their company's performance in comparison to direct industry competitors (for a similar approach, see, e.g., Huettermann and Bruch, 2019; Kunze et al., 2013). In addition, TMT members rated firm innovation with the same measure used in our study (Janssen, 2001).

To test whether our findings held when using these time-lagged and comprehensive measures of firm performance and firm innovation provided by TMT members, we replicated our research model in the subsample of 30 organizations. Due to the limited sample size and the resulting reduced statistical power, we focused on the main variables in our research model (i.e., organizational demographic faultlines, functional heterogeneity within subgroups, collective organizational identification, firm performance, and firm innovation), and included the year in which the innovation and performance ratings were obtained (i.e., one or two years after the initial data collection) as a control. Results from multiple regression analyses indicated that the interaction effect of organizational demographic faultines and functional heterogeneity within demographic subgroups on collective organizational identification remained significant in this reduced sample $(\beta=0.38, \mathrm{p}<0.05)$. In addition, collective organizational identification was positively related to the four-item firm performance measure $(\beta=0.420 .01)$ and firm innovation $(\beta=0.39, p<0.05)$. Finally, the 90 per cent bias-corrected CIs of the index of moderated mediation for both conditional indirect effects excluded zero (firm performance: index = 11.93, BootCI [2.44, 30.69]; firm innovation: index $=10.83$, BootCI $[0.31,30.15])$. Together, these results, which are based on more comprehensive assessments of firm performance provided by TMT members, point to the robustness of the findings from our main analysis. Moreover, the time lag of both outcome measures consolidates the assumed causality of the proposed relationships. ${ }^{[10]}$

\section{DISGUSSION}

This study investigates the consequences of organizational demographic faultlines. Drawing from the faultline (Lau and Murnighan, 1998) and cross-categorization literature (Sawyer et al., 2006), we develop and test a model that outlines how organizational 
demographic faultlines affect employees' collective organizational identification, and thereby indirectly influence firm performance and firm innovation. Our findings from an analysis of 82 small and medium-sized firms comprising 5,495 organizational members show that the effects of organizational demographic faultlines (based on age and gender) depend on the degree of functional heterogeneity within the faultline-based demographic subgroups. When functional heterogeneity in the subgroups is low, faultlines can harm employees' collective organizational identification, and thereby decrease firm performance and innovation. In contrast, when functional heterogeneity is high, organizational faultlines have the potential to positively influence organizational identification, performance, and innovation.

\section{Theoretical Implications}

Our study makes two important contributions to the emerging literature on organizational demographic faultlines. First, our analysis is among the first to show that organizational demographic faultlines have meaningful firm-level consequences. This finding is of particular relevance because it demonstrates that demographic faultlines have implications not only at the small-group level, but also at the level of organizations. Second, our research identifies a critical boundary condition - functional heterogeneity within faultline-based demographic subgroups - that determines whether organizational demographic faultlines have negative or positive firm-level consequences. By testing this boundary condition, we offer a nuanced understanding of the relationship between organizational demographic faultlines and collective organizational identification (and, subsequently, firm performance and firm innovation).

With our analysis, we advance both prior conceptualizations of organizational demographic faultlines and the understanding of theoretical mechanisms through which they unfold their effects. As for faultline conceptualization, there are several differences between Lawrence and Zyphur's (2011) notion of organizational faultlines and our work. Lawrence and Zyphur (2011) think of demographic subgroups created by faultlines in terms of organizational reference groups. They define such groups as the sets of people an individual perceives as belonging to her or his work environment, and making up the social world of work in which she or he engages. For Lawrence (2006), an organizational reference group includes everyone that an individual thinks of when she or he asks: Who is part of my social world at work? The group can include, for example, colleagues and friends, as well as opponents or people with whom an individual has no direct contact, such as those who are based in another building or known only through e-mail or stories. These significant others constitute the frame of reference through which individuals interpret their work experience and co-create meaning. In our conceptualization of organizational demographic faultlines, we do not think of faultline-generated subgroups as an exclusive reference group that completely determines how individuals think of workrelated issues or how they interpret their world at work. Rather, we see demographic subgroups as a possibility to relate to demographically similar others. As such, those subgroups do not necessarily involve some form of interaction - rather, subgroup members could interact with other people of their subgroup, but this is not a precondition for the effects of organizational demographic faultlines to unfold. 
Regarding the theoretical mechanisms, our study builds on the faultline literature and sheds light on the role of intergroup bias and cross-categorization to explain organizational faultlines' effects (Sawyer et al., 2006; Thatcher and Patel, 2012). Further, our argument for why the interaction of organizational demographic faultlines and high functional heterogeneity within subgroups is positively associated with collective organizational identification even goes beyond cross-categorization. Specifically, we suggest that functional heterogeneity within subgroups created by organizational faultlines not only crosscuts demographic subgroups and functional departments, but also creates a more integrated social structure. Drawing from the notion of optimal distinctiveness (Brewer, 1991), we suggest that this integrated social structure allows subgroup members to satisfy their need for differentiation, which should help them develop a more inclusive sense of identification with their organization as a whole. This argument exceeds the reasoning found in the small-group literature on cross-categorization (Thatcher and Patel, 2012).

Our theorizing is also consistent with the macro-level concept of consolidation established in sociology (Blau, 1977). Consolidation describes the strength of the positive correlation among attributes in a given population. Similar to the faultine literature, consolidation suggests that the alignment of multiple demographic attributes strengthens social relations within subgroups and reduces social bonds between subgroups (Blau, 1977). However, the higher the heterogeneity within demographic subgroups, the stronger are the expected inter-subgroup relations that strengthen 'macrosocial integration'. Viewed from the perspective of our theoretical model, the intersection of demographic subgroups and functional departments should thus increase the social integration and intergroup relations of various subgroups, improve opportunities for subgroup members, and allow them to interact with similar others across subgroup boundaries. This 'weakens ingroup bonds but improves the integration among groups' (Blau, 1977, p. 208). Similar to our theorizing built on optimal distinctiveness theory, Blau's (1977) notion of social integration through the intersection of demographic subgroups and functional departments would also imply a more inclusive sense of identification with the organization as a whole.

In addition to these contributions to the organizational faultline literature, our study also has implications for other streams of research. First, our manuscript contributes to the social identity literature by offering insights into the link between intergroup relations and collective organizational identification (Argote and Kane, 2009; Kramer, 2006; Sethi, 2000). As van Knippenberg (2003, p. 383) points out: 'A fact that is typically overlooked is that intergroup relations not only concern the relationship between different organizational groups, but also reflect upon the relationship between organizational groups and the organization as a whole'. We contribute to this literature by highlighting that intergroup relations indeed matter for employees' sense of identification with their organization as a whole. Additionally, we identify a structural condition (i.e., functional heterogeneity) under which demographic subgroups generated by organizational faultlines can reduce or enhance subgroup members' organizational identification. As such, our study also adds to a more complex understanding of employees' multiple identifications in organizations that are affected by increasingly volatile environments and societal developments, such as demographic changes (Ashforth, 2020). 
Second, our manuscript adds to the literature on intra-organizational boundary spanning by suggesting that demographic subgroups created by organizational faultlines might work as interdepartmental social networks that increase informal communication. Prior research has found that teams tend to have more external relationships with outside parties when they show high levels of functional and tenure diversity (e.g., Ancona and Caldwell, 1992; Reagans et al., 2004). This is because these types of diversity increase the variety of parties external to the team that team members might be able to reach through boundary spanning (Keller, 2001). Similarly, Burt's (2005) work on social networks suggests that individuals who act as linking pins and span different subgroups as knowledge brokers are generally well positioned to link different types of information. Accordingly, when the functional heterogeneity of demographic subgroups is high, such subgroups can provide an informal opportunity structure that allows organizational members to span departmental boundaries through informal contact with employees from other functional departments.

Third, our study adds to research on organizational innovation. Despite its longstanding tradition and the considerable amount of evidence generated with regard to potential antecedents of organizational-level innovation, prior research has been fairly silent on the role of workforce demographic composition (for an exception, see Yang and Konrad, 2011). Indeed, as a comprehensive review of the organizational innovation literature indicates, examinations of the role of diversity to date have focused mostly on the composition of the organization's TMT (Crossan and Apaydin, 2010). Our study illustrates the relevance of also considering organizational members' heterogeneity and its influence on collective organizational identification and the innovativeness of organizations.

\section{Limitations and Future Research}

As with all research, there are limitations to our study that offer opportunities for future investigations. First, our analysis is cross-sectional in nature which precludes strong causal inference. In principle, our theoretical model relates a relatively stable characteristic of an organization's demographic composition (i.e., organizational demographic faultlines) as an antecedent to the more volatile outcomes of collective organizational identification, firm performance, and firm innovation. Thus, from a conceptual perspective, the expected flow of causality is more likely than vice versa, and we are confident that our hypotheses are based on sound theoretical reasoning. Moreover, we took several measures to address potential concerns of reverse causality and endogeneity bias (Antonakis et al., 2010): (a) We replicated our findings using time-lagged data for firm performance and firm innovation for a sub-sample of companies from our main analysis (see 'Robustness Check' section); (b) we replicated our findings by controlling for companies' prior performance for another sub-sample of companies from our main analysis (see Endnote 10); (c) we used different data sources (i.e., employees, HR representatives, and TMT members) to prevent common method bias; (d) we relied on SEM techniques to account for potential measurement error; and (e) we controlled for major covariates of our outcome variables identified by prior research. Nonetheless, we cannot entirely rule out the possibility of reverse causality and therefore strongly encourage future research 
to replicate our findings using repeated measures of all variables in longitudinal and quasi-experimental designs (Meister et al., 2020).

Second, there may be additional factors that activate organizational demographic faultlines. Concurring with prior theorizing and research (e.g., Chrobot-Mason et al., 2009; Ren et al., 2015), we focused on an aspect of an organization's social structure (i.e., functional heterogeneity within demographic subgroups) as a faultline trigger. Still, there may be other and potentially even more influential factors that alter the salience of faultinebased demographic subgroups. Such faultline-related issues (Lau and Murnighan, 2005) may, for example, pertain to the intra-organizational resource allocation (e.g., organizational reward structures or interdepartmental distribution of resources; Rico et al., 2012) or social issues (e.g., conflict or competition between departments; Hart and Van Vugt, 2006). Faultline theory and research have only begun to scrutinize the process of faultline activation and how different configurations of faultline triggers can activate (or deactivate) demographic faultlines (Chrobot-Mason et al., 2009; Meister et al., 2020). Hence, future research might, for example, examine how functional heterogeneity and the history of prior interdepartmental conflicts interact in influencing organizational demographic faultlines.

A third limitation pertains to the measurement of firm performance and innovation. The firms in our sample are mostly privately-owned SMEs for which objective data on organizational effectiveness is often not publicly available. Therefore, we had to rely on subjective performance and innovation ratings by members of the TMT and key HR informants. This can be associated with certain weaknesses, such as response biases (McGrath et al., 2010). However, board members proved to be adequate key informants in prior research (Combs et al., 2005). Moreover, past research found subjective and objective indicators of organizational effectiveness to be significantly correlated (e.g., Wall et al., 2004).

Finally, although we believe our notion of organizational demographic faultines can be generalized to larger organizations, we limited our empirical focus to SMEs. We did so because we could safely assume that individuals in SMEs have some degree of geographical proximity. However, it is more difficult to think of how individuals in a multinational firm could be part of a demographic subgroup that spreads across different subsidiaries or different locations. Hence, in a larger organization with multiple geographical locations, it might be reasonable to limit the level of analysis to those parts of the firm that are geographically co-located. Further, in larger firms, the formation of faultline-based subgroups might be constrained by the number of other organizational members that employees know or see. Yet, we suggest that the general mechanism of how organizational faultlines operate in larger organizations should be similar to the mechanism found in the SMEs examined in this study.

\section{Practical Implications}

Our results are of particular relevance for organizational practice as they show that demographic faultlines not only have implications for workgroup functioning and effectiveness (Thatcher and Patel, 2012), but also have the potential to relate to the performance and innovativeness of entire organizations. Depending on additional boundary conditions, faultines can either enhance or diminish firm-level outcomes. Therefore, 
on the one hand, our findings can be seen to extend the 'business case' of diversity in organizations (Ely and Thomas, 2020; Herring, 2009) by showing that not only single diversity attributes - such as age or gender - may relate to organizational effectiveness, but that also the alignment of demographic characteristics - i.e., age and gender - matters for companies' competitive edge. On the other hand, however, decision-makers are well-advised to take action toward effectively managing the double-edged nature of organizational demographic faultlines' effects.

Specifically, our findings indicate that positive effects of organizational demographic faultlines can only be expected if members of the same age- and gender-related demographic subgroup work in different departments. Thus, to prevent negative and realize positive faultline effects, leaders and HR managers need to ensure that members of demographic subgroups based on age and gender are not only represented in specific functional departments. This implication relates closely to the more general issue of certain demographic groups being underrepresented in some professions and disciplines. For example, historically there has been an underrepresentation of women pursuing careers in science, technology, or engineering (Colwell et al., 2020). This has led to rather homogeneously composed research and development departments in many organizations that consist of mostly male and middle-aged employees. From the perspective our study, increasing the share of members from other demographic groups (e.g., younger women) in such functional departments is essential for realizing positive organizationallevel faultline effects. Thus, HR representatives should be sensitized to this issue and aim to recruit members of underrepresented age- and gender-related demographic groups to diversify the profile of specific functional departments. In this regard, organizations could also opt for targeted interventions to prevent biases in personnel selection, e.g., by implementing unconscious bias training (Emerson, 2017).

Additionally, our findings more generally point to the importance of satisfying employees' need for both differentiation and inclusion to generate positive organizationallevel faultline effects (Brewer, 1991, 1999). To promote an optimal balance between differentiation and inclusion, organizations should ensure that valuing the unique qualities of members from different demographic subgroups based on age and gender is an organizational priority. At the same time, they should stress commonalities between subgroups to foster a sense of belonging to the larger collective. To achieve this goal, organizations could foster a diversity-friendly organizational climate (McKay and Avery, 2015) that is characterized by integrating differences and allowing for the enactment of multiple identities (e.g., based on subgroup and organizational membership). In this regard, prior research has demonstrated that for such diversity-related climates to be effective, they must be similarly perceived to be inclusive by members from different demographic groups (Reinwald et al., 2019). Therefore, organizations should aim to build truly inclusive diversity-related climates, for example by offering diversity programs (Herdman and McMillan-Capehart, 2010) or inclusive leadership trainings (Nishii and Mayer, 2009). 


\section{GONGLUSION}

In this study, we examined how demographic faultlines operate at the organizational level. Drawing from faultline theory (Lau and Murnighan, 1998) and literature on crosscategorization (Sawyer et al., 2006), we showed that organizational demographic faultlines can have different effects on collective organizational identification depending on the functional heterogeneity within the faultline-based demographic subgroups. Our results show that when functional heterogeneity within these subgroups is high, organizational demographic faultlines are positively associated with collective organizational identification. In contrast, when functional heterogeneity within subgroups is low, organizational demographic faultlines are negatively related to collective organizational identification. Further, we demonstrate that by altering collective organizational identification, the interplay between organizational demographic faultlines and functional heterogeneity significantly affects firm performance and innovation. In sum, our findings suggest that organizational demographic faultlines do not necessarily generate tension among demographic subgroups and can even have positive effects on important firmlevel outcomes.

\section{AGKNOWLEDGEMENTS}

We are thankful for JMS Associate Editor Riikka Sarala, the second anonymous senior editor, and the three anonymous reviewers for their thoughtful comments and a developmental review process, as well as Tina Petersen, Cynthia Lambert, and Christine Anthonissen for their expert copy editing. We thank Bertolt Meyer, Kate Bezrukova, Andrew Carton, and Max Reinwald for their constructive feedback on earlier versions of the manuscript, as well as Daniel Fauser and Dominik Miklec for their help in curating the data set of our supplementary analysis. We are also grateful for feedback provided by seminar attendees at the University of St. Gallen and University of Groningen and by participants at the Academy of Management Annual Meeting and the INGroup conference. This research was supported by the Basic Research Fund of the University of St. Gallen.

\section{NOTES}

[1] Note that analysing the effects of organizational demographic faultlines dependent on functional heterogeneity requires a moderator analysis. If we only included functional department membership as an additional attribute in our faultine conceptualization (and measurement), we could examine the condition when demographic attributes and this additional characteristic are aligned (i.e., low functional heterogeneity within demographic subgroups), but not the condition when demographic attributes and this additional characteristic are not aligned (i.e., high functional heterogeneity within demographic faultlines; e.g., Homan et al., 2007).

[2] We found no significant differences in terms of employee age $(F=0.26, \mathrm{p}<0.90)$ and gender $(F=0.92$, $\mathrm{p}<0.30)$ among survey versions $(A-D)$. Hence, we concluded that randomly assigning participants to different survey versions worked as expected.

[3] Data-protection restrictions in Germany precluded the use of archival data for demographic attributes. Therefore, we had to rely on employees' self-reports, especially for matching their age and gender with their department membership.

[4] We validated our ASW faultline algorithm by testing whether individuals who were predicted to be in a particular demographic subgroup had more social network links with individuals from the same demographic subgroup than with people from another subgroup. This validation study's aim was to see whether the assumption holds that people tend to have more communication with members of the same demographic subgroup than with members of other subgroups. To do so, we drew from a dataset 
used by Lawrence (2006) and Lawrence and Zyphur (2011). This dataset comprises a systematic and stratified sample of 411 managers in a large utility company with more than 9,000 employees (gender: 23 per cent women; average age: 44 years [23-74 years]; educational level: 65 per cent college degree; average organizational tenure: 17 years [0-50 years]). To calculate a ratio between external and internal network ties (i.e., links within the same subgroup versus links to another subgroup), we used Krackardt and Stern's (1988) external-internal (E-I) index, as this measure takes subgroup sizes into account: $E-I$ index $=\frac{E L-I L}{E L+I L}$, where EL denotes the number of external ties (i.e., links to another subgroup) and IL refers to the number of internal ties (i.e., links within the same subgroup). The possible scores of the index range from -1 to +1 . When the E-I index approaches -1 , all ties are internal (i.e., within the same demographic subgroup). Conversely, when the E-I index approaches +1 , all ties are external (i.e., with another subgroup) (Krackardt and Stern, 1988). We found an average E-I index across communication ties of $-0.14(S D=0.75)$, which suggests that individuals tend to have more social network ties within demographic subgroups generated by faultlines than they have between those subgroups. A significant t-test between the number of internal and external ties supports these results $(T=7,41, d f=4108, \mathrm{p}<0.001)$.

[5] Drawing again from the dataset used by Lawrence (2006) and Lawrence and Zyphur (2011), we compared the agreement of subgroup membership as predicted by the ASW algorithm with the subgroup membership as predicted by the latent class cluster analysis (LCGA) algorithm used by Lawrence and Zyphur (2011) in their faultline operationalization. We did so using Cramér's V, which is a measure standardized between 0 and 1 that evaluates the strength of an association between nominal variables (Cramér, 1946). The results suggest that ASW and LCCA predict fairly similar subgroup memberships (Cramér's $V=0.58, \mathrm{p}<001$ ). We then used our dataset of 82 small- and medium-sized organizations to test the agreement of subgroup membership as predicted by the ASW and the LCCA algorithm. To ensure that an organization's size does not influence the similarity of predicted subgroup membership, we examined the two largest firms in our data $(\mathcal{N}=246, \mathrm{~N}=220)$ and the two smallest firms (NC: $\mathcal{N}=22$, D: $\mathcal{N}=20$ ). Again, we found significant Cramér's $V_{\mathrm{s}}$ (ranging from.70 to.89), suggesting that ASW and LCCA predict highly similar subgroup memberships. Apart from these empirical similarities, LCCA has disadvantages relative to ASW. First, for group sizes of less than 30, LCGA can deliver unstable results and can fail to converge (Nylund et al., 2007; Meyer and Glenz, 2013). Second, LCGA has difficulties finding clusters in the case of binary categorical variables (such as gender). Hence, we suggest that ASW has more favourable empirical properties than the LCCA algorithm, especially against the background of our conceptual focus on demographic faultlines involving the binary categorical variable of gender and our sample, which includes organizations with less than 30 organizational members.

[6] To examine the robustness of our results, we repeated our analysis without including the insignificant control variables (Becker, 2005). This analysis did not change our conclusions regarding our hypotheses.

[7] For 5 of the 82 organizations, HR representatives did not provide data on firm performance. For 22 organizations, TMT members did not provide data on firm innovation.

[8] In a sensitivity analysis, we used an alternative definition of small and medium-sized organizations, and included all organizations with up to 500 organizational members $(\mathcal{N}=108)$ (United States International Trade Commission, 2010). For these additional 36 organizations, we assumed that employees might still know each other across functional departments. This analysis did not change our conclusions regarding our hypotheses, which suggests that our findings can also be generalized to somewhat larger organizations than those originally studied, i.e., ones with up to 250 employees.

[9] Given our relatively low sample size, we acknowledge that the number of cases is at the lower end of acceptable sample sizes for structural equation modelling. To test our findings' reliability, we replicated our model using path analysis without including the control variables. This analysis exceeded the commonly discussed standard of a cases-to-parameter ratio of 5:1 (e.g., Brown, 2006; Kline, 2011). This additional analysis did not change our results-based conclusions. Therefore, we are confident that our analysis is not compromised by the relatively low sample size.

[10] To further address potential endogeneity concerns, we contacted the benchmarking agency with which we had cooperated and asked them whether any of the companies from our sample had participated in another benchmarking study in the two years prior to our data collection. We were able to obtain prior firm performance data for a subsample of $\mathrm{N}=20$ companies from our main analysis. Similar to our main study, top HR representatives rated their company's overall performance by comparing it with direct industry competitors (Rogers and Wright, 1998). We re-ran our analyses with this subsample of companies and included prior firm performance as a control variable. Due to the small sample size, we included only the main variables from our conceptual model (i.e., organizational demographic faultlines, functional heterogeneity within subgroups, collective organizational identification, firm 
performance, and firm innovation), and additionally controlled for the year in which the performance rating was obtained (i.e., one or two years before the data collection for our main study). Results from multiple regression analyses showed that there was still a significant interaction between organizational demographic faultlines and functional heterogeneity when we controlled for prior firm performance in this sub-sample $(\beta=0.44, \mathrm{p}<0.05)$. Similarly, when controlling for prior firm performance, we found collective organizational identification still significantly related to the firm performance $(\beta=0.63$, $\mathrm{p}<0.05)$ and firm innovation $(\beta=0.59, \mathrm{p}<0.10)$ measures of our main study. In sum, these findings suggest a certain robustness of our results against endogeneity bias, although they should be considered with caution due to the small sample size.

\section{REFERENCES}

Aiken, L. S. and West, S. G. (1991). Multiple Regression: Testing and Interpreting Interactions. Newbury Park, CA: Sage.

Albert, S., Ashforth, B. E. and Dutton, J. E. (2000). 'Organizational identity and identification: Charting new waters and building new bridges'. Academy of Management Review, 25, 13-17.

Ancona, D. G. and Caldwell, D. F. (1992). 'Bridging the boundary: External activity and performance in organizational teams'. Administrative Science Quarterly, 37, 634-65.

Anderson, N. R., De Dreu, C. K. W. and Nijstad, B. A. (2004). 'The routinization of innovation research: A constructively critical review of the state-of-the-science'. Fournal of Organizational Behavior, 25, 147-73.

Antonakis, J., Bendahan, S., Jacquart, P. and Lalive, R. (2010). 'On making causal claims: A review and recommendations'. The Leadership Quarterly, 21, 1086-120.

Argote, L. and Kane, A. A. (2009). 'Superordinate identity and knowledge creation and transfer in organizations'. In Foss, N. J. and Michailova, S. (Eds), Knoweledge Governance. Oxford: Oxford University Press, $166-90$.

Ashforth, B. E. (2020). 'Identity and identification during and after the pandemic: How might Covid-19 change the research questions we ask?' Journal of Management Studies, 57, 1763-66.

Ashforth, B. E., Harrison, S. H. and Corley, K. G. (2008). 'Identification in organizations: An examination of four fundamental questions'. Fournal of Management, 34, 325-74.

Ashforth, B. E. and Johnson, S. A. (2001). 'Which hat to wear? The relative salience of multiple identities in organizational contexts'. In Hogg, M. A. and Terry, D. J. (Eds), Social Identity Processes in Organizational Contexts. Ann Arbor, MI: Taylor \& Francis, 31-48.

Ashforth, B. E. and Mael, F. (1989). 'Social identity theory and the organization'. Academy of Management Revierw, 14, 20-39.

Bagozzi, R. P. and Edwards, J. R. (1998). 'A general approach for representing constructs in organizational research'. Organizational Research Methods, 1, 45-87.

Bagozzi, R. P. and Yi, Y. (1988). 'On the evaluation of structural equation models'. Fournal of the Academy of Marketing Science, 16, 74-94.

Barrick, M. R., Thurgood, G. R., Smith, T. A. and Courtright, S. H. (2015). 'Collective organizational engagement: Linking motivational antecedents, strategic implementation, and firm performance'. Academy of Management Fournal, 58, 111-35.

Becker, T. E. (2005). 'Potential problems in the statistical control of variables in organizational research: A qualitative analysis with recommendations'. Organizational Research Methods, 8, 274-89.

Berger, S., van de Brake, H. J. and Bruch, H. (2021). 'Resource leverage, resource depletion: A multilevel perspective on multiple team membership'. Fournal of Applied Psychology. https://doi.org/10.1037/apl00 00889.

Bezrukova, K., Spell, C. S., Caldwell, D. and Burger, J. M. (2016). 'A multilevel perspective on faultlines: Differentiating the effects between group- and organizational-level faultlines'. Fournal of Applied Psychology, 101, 86-107.

Bezrukova, K. and Uparna, J. (2009). 'Group splits and culture shifts: A new map of the creativity terrain'. In Mannix, E. A., Goncalo, J. A. and Neale, M. A. (Eds), Creativity in Groups (Research on Managing Groups and Teams, vol. 12). Bingley: Emerald, 163-93.

Blau, P. M. (1977). Inequality and Heterogeneity. New York: Free Press.

Brewer, M. B. (1991). 'The social self: On being the same and different at the same time'. Personality and Social Psychology Bulletin, 17, 475-82.

Brewer, M. B. (1996). 'When contact is not enough: Social identity and intergroup cooperation'. International Fournal of Intercultural Relations, 20, 291-303. 
Brewer, M. B. (1999). 'The psychology of prejudice: Ingroup love or outgroup hate?'. Fournal of Social Issues, 55, 429-44.

Brislin, R. W. (1986). 'The wording and translation of research instruments'. In Lonner, W. J. and Berry, J. W. (Eds), Field Methods in Cross-Cultural Research. Thousand Oaks, CA: Sage, 137-64.

Brown, T. A. (2006). Confirmatory Factor Analysis for Applied Research. New York: Guilford.

Bunderson, J. S. and Sutcliffe, K. M. (2002). 'Comparing alternative conceptualizations of functional diversity in management teams: Process and performance effects'. Academy of Management fournal, 45, 875-93.

Burt, R. S. (2005). Brokerage and Closure: An Introduction to Social Capital. Oxford: Oxford University Press.

Carmeli, A., Cohen-Meitar, R. and Elizur, D. (2007). 'The role of job challenge and organizational identification in enhancing creative behavior among employees in the workplace'. Fournal of Creative Behavior, 41, 75-90.

Carton, A. M. and Cummings, J. N. (2013). 'The impact of subgroup type and subgroup configurational properties on work team performance'. Fournal of Applied Psychology, 98, 732-58.

Chan, D. (1998). 'Functional relations among constructs in the same content domain at different levels of analysis: A typology of composition models'. Fournal of Applied Psychology, 83, 234-46.

Choi, Y. R. and Shepherd, D. A. (2005). 'Stakeholder perceptions of age and other dimensions of newness'. fournal of Management, 31, 573-96.

Chrobot-Mason, D., Ruderman, M. N., Weber, T. J. and Ernst, C. (2009). 'The challenge of leading on unstable ground: Triggers that activate social identity faultlines'. Human Relations, 62, 1763-94.

Chung, Y., Liao, H., Jackson, S. E., Subramony, M., Colakoglu, S. and Jiang, Y. (2015). 'Cracking but not breaking: Joint effects of faultline strength and diversity climate on loyal behavior'. Academy of Management fournal, 58, 1495-515.

Colwell, R. R., Bear, A. and Helman, A. (2020). Promising Practices for Addressing the Underrepresentation of Women in Science, Engineering, and Medicine: Opening Doors. Washington, DC: National Academies Press.

Combs, J. G., Crook, T. R. and Shook, C. L. (2005). 'The dimensionality of organizational performance and its implications for strategic management research'. In Ketchen, D. J. and Bergh, D. D. (Eds), Research Methodology in Strategy and Management. Vol. 2. Oxford: Elsevier, 259-86.

Cox, T. H. Jr. (1994). Cultural Diversity in Organizations: Theory, Research, \& Practice. San Francisco, CA: Berrett-Koehler.

Cramér, H. (1946). Mathematical Methods of Statistics. Princeton, NJ: Princeton University Press.

Crossan, M. M. and Apaydin, M. (2010). 'A multi-dimensional framework of organizational innovation: A systematic review of the literature'. Fournal of Management Studies, 47, 1154-91.

Damanpour, F. (1991). 'Organizational innovation: A meta-analysis of determinants and moderators'. Academy of Management fournal, 34, 555-90.

Damanpour, F. (2020). Organizational Innovation: Theory, Research, and Direction. Cheltenham: Elgar.

DeStatis. (Ed.) (2018). Deutschland hat die zweithöchste Erwerbstätigenquote der EU; Pressemitteilung Nr. 461 [Germany has the Second Highest Employment Rate in the EU; Press Release No. 461]. Wiesbaden, Germany: German Federal Statistical Office.

DeStatis. (Ed.) (2019). Koordinierte Bevölkerungsvorausrechnung für Deutschland [Coordinated Population Estimation for Germany]. Wiesbaden, Germany: German Federal Statistical Office.

Dickson, M. W., Resick, C. J. and Hanges, P. J. (2006). 'Systematic variation in organizationally-shared cognitive prototypes of effective leadership based on organizational form'. The Leadership Quarterly, 17, 487-505.

Ely, R. J. and Thomas, D. A. (2020). 'Getting serious about diversity'. Harvard Business Review, 98, $114-22$.

Emerson, J. (2017). 'Don't give up on unconscious bias training - Make it better'. Harvard Business Review Digital Article. Available at: https: / / hbr.org/2017/04/dont-give-up-on-unconscious-bias-training-makeit-better (accessed 20 December 2020).

Enders, C. K. and Bandalos, D. L. (2001). 'The relative performance of full information maximum likelihood estimation for missing data in structural equation models'. Structural Equation Modeling, 8, 430-57.

European Commission (2017). What is an SME?. European Commission. Available at: http://ec.europa.eu/ growth/smes/business-friendly-environment/sme-definition_en

Fornell, C. and Larcker, D. F. (1981). 'Evaluating structural equation models with unobservable variables and measurement errors'. Fournal of Marketing Research, 18, 39-50.

Ganster, D. C. and Dwyer, D. J. (1995). 'The effects of understaffing on individual and group performance in professional and trade occupations'. Fournal of Management, 21, 175-90.

Gardner, T. M., Wright, P. M. and Moynihan, L. M. (2011). 'The impact of motivation, empowerment, and skill-enhancing practices on aggregate voluntary turnover: The mediating effect of collective affective commitment'. Personnel Psychology, 64, 315-50. 
Gibson, C. B. and Vermeulen, F. (2003). 'A healthy divide: Subgroups as a stimulus for team learning behavior'. Administrative Science Quarterly, 48, 202-39.

Grice, T. A., Gallois, C., Jones, E., Paulsen, N. and Callan, V. J. (2006). 'We do it, but they don't: Multiple categorizations and work team communication'. Fournal of Applied Communication Research, 34, 331-48.

Hage, J. T. (1999). 'Organizational innovation and organizational change'. Annual Review of Sociology, 25, 597-622.

Harrison, D. A. and Klein, K. J. (2007). 'What's the difference? Diversity constructs as separation, variety, or disparity in organizations'. Academy of Management Review, 32, 1199-228.

Harrison, D. A., Price, K. H. and Bell, M. P. (1998). 'Beyond relational demography: Time and the effects of surface- and deep-level diversity on work group cohesion'. Academy of Management fournal, 41, 96-107.

Hart, C. M. and Van Vugt, M. (2006). 'From fault line to group fission: Understanding membership changes in small groups'. Personality and Social Psychology Bulletin, 32, 392-404.

Haslam, S. A. and Ellemers, N. (2005). 'Social identity in industrial and organizational psychology: Concepts, controversies and contributions'. International Review of Industrial and Organizational Psychology, 20, 39-118.

Hayes, A. F. (2015). 'An index and test of linear moderated mediation'. Multivariate Behavioral Research, 50, 1-22.

Hennessey, B. A. and Amabile, T. M. (2010). 'Creativity'. Annual Review of Psychology, 61, 569-98.

Herdman, A. and McMillan-Capehart, A. (2010). 'Establishing a diversity program is not enough: Exploring the determinants of diversity climate'. Fournal of Business \& Psychology, 25, 39-53.

Herring, C. (2009). 'Does diversity pay? Race, gender, and the business case for diversity'. American Sociological Review, 74, 208-24.

Hogg, M. A. and Abrams, D. (1988). Social Identifications - A Social Psychology of Intergroup Relations and Group Processes. London: Routledge.

Homan, A. C., van Knippenberg, D., van Kleef, G. A. and De Dreu, C. K. W. (2007). 'Interacting dimensions of diversity: Cross-categorization and the functioning of diverse work groups'. Group Dynamics: Theory, Research, and Practice, 11, 79-94.

Huettermann, H. and Bruch, H. (2019). 'Mutual gains? Health-related HRM, collective well-being and organizational performance'. Fournal of Management Studies, 56, 1045-72.

James, L. R., Demaree, R. G. and Wolf, G. (1984). 'Estimating within-group interrater reliability with and without response bias'. Journal of Applied Psychology, 69, 85-98.

Janssen, O. (2001). 'Fairness perceptions as a moderator in the curvilinear relationships between job demands, and job performance and job satisfaction'. Academy of Management fournal, 44, 1039-50.

Jehn, K. A. and Bezrukova, K. (2010). 'The faultline activation process and the effects of activated faultlines on coalition formation, conflict, and group outcomes'. Organizational Behavior and Human Decision Processes, 112, 24-42.

Kane, A. A., Argote, L. and Levine, J. M. (2005). 'Knowledge transfer between groups via personnel rotation: Effects of social identity and knowledge quality'. Organizational Behavior and Human Decision Processes, 96, 56-71.

Kanter, R. M. (1988). 'When a thousand flowers bloom: Structural, structural, collective, and social conditions for innovation in organizations'. In Staw, B. M. and Cummings, L. L. (Eds), Research in Organizational Behavior. Vol. 10. Greenwich, CT: JAI Press, 169-211.

Kearney, E. and Gebert, D. (2009). 'Managing diversity and enhancing team outcomes: The promise of transformational leadership'. Fournal of Applied Psychology, 94, 77-89.

Keller, R. T. (2001). 'Cross-functional project groups in research and new product development: Diversity, communications, job stress, and outcomes'. Academy of Management fournal, 44, 547-55.

Kline, R. B. (2011). Principles and Practice of Structural Equation Modeling. New York: Guilford Publications.

Kopelman, R. E., Brief, A. P. and Guzzo, R. A. (1990). 'The role of climate and culture in productivity'. In Schneider, B. (Ed.), Organizational Climate and Culture. San Francisco, CA: Jossey-Bass, 282-318.

Krackhardt, D. and Stern, R. N. (1988). 'Informal networks and organizational crises: An experimental simulation'. Social Psychology Quarterly, 51, 123-40.

Kramer, R. M. (2006). 'Social capital and cooperative behavior in the workplace: A social identity perspective'. Advances in Group Processes, 23, 1-30.

Kunze, F., Boehm, S. A. and Bruch, H. (2011). 'Age diversity, age discrimination climate and performance consequences - A cross-organizational study'. Journal of Organizational Behavior, 32, 264-90.

Kunze, F., Boehm, S. A. and Bruch, H. (2013). 'Organizational performance consequences of age diversity: Inspecting the role of diversity-friendly HR policies and top managers' negative age stereotypes'. Fournal of Management Studies, 50, 413-42.

Larson, J. (2009). In Search of Synergy in Small Group Performance. New York: Psychology Press. 
Lau, D. C. and Murnighan, J. K. (1998). 'Demographic diversity and faultlines: The compositional dynamics of organizational groups'. Academy of Management Review, 23, 325-40.

Lau, D. C. and Murnighan, J. K. (2005). 'Interactions within groups and subgroups: The effects of demographic faultlines'. Academy of Management fournal, 48, 645-59.

Lawrence, B. S. (2006). 'Organizational reference groups: A missing perspective on social context'. Organization Science, 17, 80-100.

Lawrence, B. and Shah, N. (2020). 'Homophily: Measures and meaning'. Academy of Management Annals, 14, 513-97.

Lawrence, B. S. and Zyphur, M.J. (2011). 'Identifying organizational faultlines with latent class cluster analysis'. Organizational Research Methods, 14, 32-57.

LeBreton, J. M. and Senter, J. L. (2008). 'Answers to 20 questions about interrater reliability and interrater agreement'. Organizational Research Methods, 11, 815-52.

Lee, E.-S., Park, T.-Y. and Koo, B. (2015). 'Identifying organizational identification as a basis for attitudes and behaviors: A meta-analytic review'. Psychological Bulletin, 141, 1049-80.

Linton, R. (1942). 'Age and sex categories'. American Sociological Review, 7, 589-603.

Loi, R., Chan, K. W. and Lam, L. W. (2014). 'Leader-member exchange, organizational identification, and job satisfaction: A social identity perspective'. Fournal of Occupational and Organizational Psychology, 87, 42-61.

Mael, F. and Ashforth, B. E. (1992). 'Alumni and their alma mater: A partial test of the reformulated model of organizational identification'. Fournal of Organizational Behavior, 13, 103-23.

Marcus-Newhall, A., Miller, N., Holtz, R. and Brewer, M. B. (1993). 'Cross-cutting category membership with role assignment: A means of reducing intergroup bias'. British fournal of Social Psychology, 32 , 125-46.

Mäs, M., Flache, A., Takacs, K. and Jehn, K. A. (2013). 'In the short term we divide, in the long term we unite: Demographic crisscrossing and the effects of faultlines on subgroup polarization'. Organization Science, 24, 716-36.

McGrath, R. E., Mitchell, M., Kim, B. H. and Hough, L. (2010). 'Evidence for response bias as a source of error variance in applied assessment'. Psychological Bulletin, 136, 450-70.

McGregor, D. (1960). The Human Side of Enterprise. New York: McGraw-Hill.

McKay, P. F. and Avery, D. R. (2015). 'Diversity climate in organizations: Current wisdom and domains of uncertainty'. In Wheeler, A. R. and Halbesleben, J. R. B. (Eds), Research in Personnel and Human Resources Management. Bingley: Emerald Group, 191-233.

Meister, A., Thatcher, S. M. B., Park, J. and Maltarich, M. (2020). 'Toward a temporal theory of faultlines and subgroup entrenchment'. Journal of Management Studies, 57, 1473-501.

Meyer, B. and Glenz, A. (2013). 'Team faultline measures: A computational comparison and a new approach to multiple subgroups'. Organizational Research Methods, 16, 393-424.

Meyer, B., Glenz, A., Antino, M., Rico, R. and González-Romá, V. (2014). 'Faultlines and subgroups: A meta-review and measurement guide'. Small Group Research, 45, 633-70.

Meyer, B., Shemla, M., Li, J. and Wegge, J. (2015). 'On the same side of the faultline: Inclusion in the leader's subgroup and employee performance'. Fournal of Management Studies, 52, 354-80.

Migdal, M. J., Hewstone, M. and Mullen, B. (1998). 'The effects of crossed categorization on intergroup evaluations: A meta-analysis'. British fournal of Social Psychology, 37, 303-24.

Milliken, F. J. and Martins, L. L. (1996). 'Searching for common threads: Understanding the multiple effects of diversity in organizational groups'. Academy of Management Review, 21, 402-33.

Morgeson, F. P. and Hofmann, D. A. (1999). 'The structure and function of collective constructs: Implications for multilevel research and theory development'. Academy of Management Review, 24, 249-65.

Muthén, L. K. and Muthén, B. O. (1998-2019). Mplus User’s Guide. 8th. edition. Los Angeles, CA: Muthén \& Muthén.

Nishii, L. H. and Goncalo, J. A. (2008). 'Demographic faultlines and creativity in diverse groups'. In Phillips, K. W. (Ed.), Research on Managing Groups and Teams. Vol. 11. Bingley: JAI, 1-26.

Nishii, L. H. and Mayer, D. M. (2009). 'Do inclusive leaders help to reduce turnover in diverse groups? The moderating role of leader-member-exchange in the diversity to turnover relationship'. Fournal of Applied Psychology, 94, 1412-26.

Nylund, K. L., Asparouhov, T. and Muthén, B. O. (2007). 'Deciding on the number of classes in latent class analysis and growth mixture modeling: A Monte Carlo simulation study'. Structural Equation Modeling, 14, 535-69.

Ormiston, M. E. and Wong, E. M. (2012). 'The gleam of the double-edged sword: The benefits of subgroups for organizational ethics'. Psychological Science, 23, 400-403. 
Ostroff, G. (1992). 'The relationship between satisfaction, attitudes, and performance: An organizational level analysis'. Journal of Applied Psychology, 77, 963-74.

Phillips, K. W., Mannix, E. A., Neale, M. A. and Gruenfeld, D. H. (2004). 'Diverse groups and information sharing: The effects of congruent ties'. Fournal of Experimental Social Psychology, 40, 497-510.

Pierce, J. L. and Gardner, D. G. (2004). 'Self-esteem within the work and organizational context: A review of the organization-based self-esteem literature'. Journal of Management, 30, 591-622.

Podsakoff, P. M., MacKenzie, S. B., Lee, J. Y. and Podsakoff, N. P. (2003). 'Common method biases in behavioral research: A critical review of the literature and recommended remedies'. Fournal of Applied Psychology, 88, 879-903.

Polzer, J. T., Crisp, C. B., Jarvenpaa, S. L. and Kim, J. W. (2006). 'Extending the faultline model to geographically dispersed teams: How colocated subgroups can impair group functioning'. Academy of Management fournal, 49, 679-92.

Pratt, M. G. (1998). 'To be or not to be? Central questions in organizational identification'. In Whetten, D. A. and Godfrey, P. C. (Eds), Identity in Organizations: Building Theory Through Conversations. Thousand Oaks, CA: Sage, 171-207.

Preacher, K. J. and Hayes, A. F. (2008). 'Asymptotic and resampling strategies for assessing and comparing indirect effects in multiple mediator models'. Behavior Research Methods, 40, 879-91.

Reagans, R., Zuckerman, E. and McEvily, B. (2004). 'How to make the team: Social networks vs. demography as criteria for designing effective teams'. Administrative Science Quarterly, 49, 101-33.

Reinwald, M., Huettermann, H. and Bruch, H. (2019). 'Beyond the mean: Understanding firm-level consequences of variability in diversity climate perceptions'. Fournal of Organizational Behavior, 40, 472-91.

Ren, H., Gray, B. and Harrison, D. A. (2015). 'Triggering faultline effects in teams: The importance of bridging friendship ties and breaching animosity ties'. Organization Science, 26, 390-404.

Rico, R., Sanchez-Manzanares, M., Antino, M. and Lau, D. (2012). 'Bridging team faultlines by combining task role assignment and goal structure strategies'. Fournal of Applied Psychology, 97, 407-20.

Riketta, M. (2005). 'Organizational identification: A meta-analysis'. Fournal of Vocational Behavior, 66, 358-84.

Riketta, M. and van Dick, R. (2005). 'Foci of attachment in organizations: A meta-analytic comparison of the strength and correlates of workgroup versus organizational identification and commitment'. Fournal of Vocational Behavior, 67, 490-510.

Rogers, E. W. and Wright, P. M. (1998). 'Measuring organizational performance in strategic human resource management: Problems, prospects and performance information markets'. Human Resource Management Review, 8, 311-31.

Rousseeuw, P. J. (1987). 'Silhouettes: A graphical aid to the interpretation and validation of cluster analysis'. Fournal of Computational and Applied Mathematics, 20, 53-65.

Russo, T. C. (1998). 'Organizational and professional identification: A case of newspaper journalists'. Management Communication Quarterly, 12, 72-111.

Sawyer, J. E., Houlette, M. A. and Yeagley, E. L. (2006). 'Decision performance and diversity structure: Comparing faultlines in convergent, crosscut, and racially homogeneous groups'. Organizational Behavior and Human Decision Processes, 99, 1-15.

Sethi, R. (2000). 'New product quality and product development teams'. Fournal of Marketing, 64, 1-14.

Tajfel, H. (1978). 'Social categorization, social identity and social comparison'. In Tajfel, H. (Ed.), Differentiation Between Social Groups: Studies in the Social Psychology of Intergroup Relations. London: Academic Press, 61-76.

Tajfel, H. and Turner, J. C. (1986). 'Social identity theory and intergroup behavior'. In Worchel, S. and Austin, W. G. (Eds), Psychology of Intergroup Relations. Chicago, IL: Nelson-Hall, 7-24.

Thatcher, S. M. B., Jehn, K. A. and Zanutto, E. (2003). 'Cracks in diversity research: The effects of diversity faultlines on conflict and performance'. Group Decision and Negotiation, 12, 217-41.

Thatcher, S. M. B. and Patel, P. C. (2012). 'Group faultlines: A review, integration, and guide to future research'. Fournal of Management, 38, 969-1009.

Turner, J. C. (1984). 'Social identification and psychological group formation'. In Tajfel, H. (Ed.), The social Dimension: European Developments in Social Psychology. New York: Cambridge University Press, 518-38.

United States International Trade Commission (2010). Small and Medium-Sized Enterprises: Overview of Participation in U.S. Exports. Available at: https://www.usitc.gov/publications/332/pub4125.pdf

van der Vegt, G. S. and Bunderson, J. S. (2005). 'Learning and performance in multidisciplinary teams: The importance of collective team identification'. Academy of Management fournal, 48, 532-47.

van Knippenberg, D. (2000). 'Work motivation and performance: A social identity perspective'. Applied Psychology: An International Review, 49, 357-71. 
van Knippenberg, D. (2003). 'Intergroup relations in organizations'. In West, M. A., Tjosvold, D. and Smith, K. G. (Eds), International Handbook of Organizational Teamwork and Cooperative Working. Hoboken, NJ: Wiley, 381-400.

van Knippenberg, D., De Dreu, C. K. W. and Homan, A. C. (2004). 'Work group diversity and group performance: An integrative model and research agenda'. Fournal of Applied Psychology, 89, 1008-22.

van Knippenberg, D. and Schippers, M. C. (2007). 'Work group diversity'. Annual Review of Psychology, 58, 515-41.

van Knippenberg, D. and van Schie, E. C. M. (2000). 'Foci and correlates of organizational identification'. Fournal of Occupational \& Organizational Psychology, 73, 137-47.

Wall, T. D., Michie, J., Patterson, M., Wood, S. J., Sheehan, M., Clegg, C. W. and West, M. A. (2004). 'On the validity of subjective measures of company performance'. Personnel Psychology, 57, 95-118.

West, M. A. and Farr, J. L. (1990). 'Innovation at work'. In West, M. A. and Farr, J. L. (Eds), Innovation and Creativity at Work: Psychological and Organizational Strategies. Chichester: John Wiley \& Sons, 3-13.

Williams, K. Y. and O'Reilly, C. A. (1998). 'Demography and diversity in organizations: A review of 40 years of research'. In Staw, B. M. and Sutton, R. M. (Eds), Research in Organizational Behavior. Vol. 20. Stamford, CT: JAI Press, 77-140.

Wolfe, R. A. (1994). 'Organizational innovation: Review, critique and suggested research directions'. Fournal of Management Studies, 31, 405-31.

Yang, Y. and Konrad, A. M. (2011). 'Diversity and organizational innovation: The role of employee involvement'. Fournal of Organizational Behavior, 31, 1062-83.

\section{APPENDIX}

\section{GALGULATION OF AVERAGE SILHOUETTE WIDTH (ASW) ALGORITHM}

The ASW algorithm identifies subgroups and calculates faultline strength based on a stepwise cluster analysis. In the first step, all members of the entity under study (in our case, the members of one of the organizations participating in our analysis) are assigned to their own subgroup (i.e., subgroup size $=1$ ). Subsequently, cluster analysis proceeds and, iteratively, clusters (i.e., subgroups) with organizational members that are very similar (in our case, in terms of age and gender) are merged stepwise into new, larger subgroups. This process continues until all organizational members belong to the same cluster (i.e., the entire organization; Meyer et al., 2014, 2015).

For each of the intermediate clustering steps, the algorithm calculates the ASW value, which is the average silhouette width (Rousseeuw, 1987) for each organizational member. The individual silhouette width is based on the following formula:

$$
s(i)=\frac{b_{i}-a_{i}}{\max \left(a_{i}, b_{i}\right)},
$$

where $a_{i}$ denotes the average dissimilarity of $i$ to all members of cluster $A$ and $b_{i}$ refers to the average dissimilarity of $i$ to all members of cluster $B$. If there are more than two subgroups, $b_{i}$ is calculated as the minimum average dissimilarity to any cluster other than A. Thereby, dissimilarities are calculated as Euclidean distances between two individuals. Silhouette widths range from -1 to +1 , with a value of 1 indicating the strongest possible association with a cluster (i.e., subgroup; Meyer and Glenz, 2013).

The silhouette width indicates how well an organizational member fits into his or her cluster or subgroup (in our case, based on age and gender). Therefore, the average silhouette width provides information on all organizational members' average fit to their respective cluster or subgroup in a specific clustering step (Meyer et al., 2015). The ASW values for all clustering steps are retained in the algorithm's memory. In the end, for each organization under study, the subgroup configuration from the clustering step that returns the highest ASW value is chosen, as it reflects the scenario in which there are clusters or subgroups that have maximum internal homogeneity and maximum heterogeneity between clusters (in our case, regarding age and gender). The ASW algorithm also provides information on the number and size of the clusters or subgroups identified with the configuration that yields the highest ASW value (see Meyer and Glenz, 2013, for additional information on the ASW procedure). 